\title{
An Extension Strain Type Mohr-Coulomb Criterion
}

\author{
Manfred Staat ${ }^{1}$ (D)
}

Received: 14 March 2021 / Accepted: 5 August 2021 / Published online: 20 August 2021

(c) The Author(s) 2021

\begin{abstract}
Extension fractures are typical for the deformation under low or no confining pressure. They can be explained by a phenomenological extension strain failure criterion. In the past, a simple empirical criterion for fracture initiation in brittle rock has been developed. In this article, it is shown that the simple extension strain criterion makes unrealistic strength predictions in biaxial compression and tension. To overcome this major limitation, a new extension strain criterion is proposed by adding a weighted principal shear component to the simple criterion. The shear weight is chosen, such that the enriched extension strain criterion represents the same failure surface as the Mohr-Coulomb (MC) criterion. Thus, the MC criterion has been derived as an extension strain criterion predicting extension failure modes, which are unexpected in the classical understanding of the failure of cohesive-frictional materials. In progressive damage of rock, the most likely fracture direction is orthogonal to the maximum extension strain leading to dilatancy. The enriched extension strain criterion is proposed as a threshold surface for crack initiation CI and crack damage CD and as a failure surface at peak stress CP. Different from compressive loading, tensile loading requires only a limited number of critical cracks to cause failure. Therefore, for tensile stresses, the failure criteria must be modified somehow, possibly by a cut-off corresponding to the CI stress. Examples show that the enriched extension strain criterion predicts much lower volumes of damaged rock mass compared to the simple extension strain criterion.
\end{abstract}

Keywords Extension fracture - Simple extension strain criterion $\cdot$ Enriched extension strain criterion $\cdot$ Mohr-Coulomb criterion $\cdot$ Low confinement $\cdot$ Evolution of damage

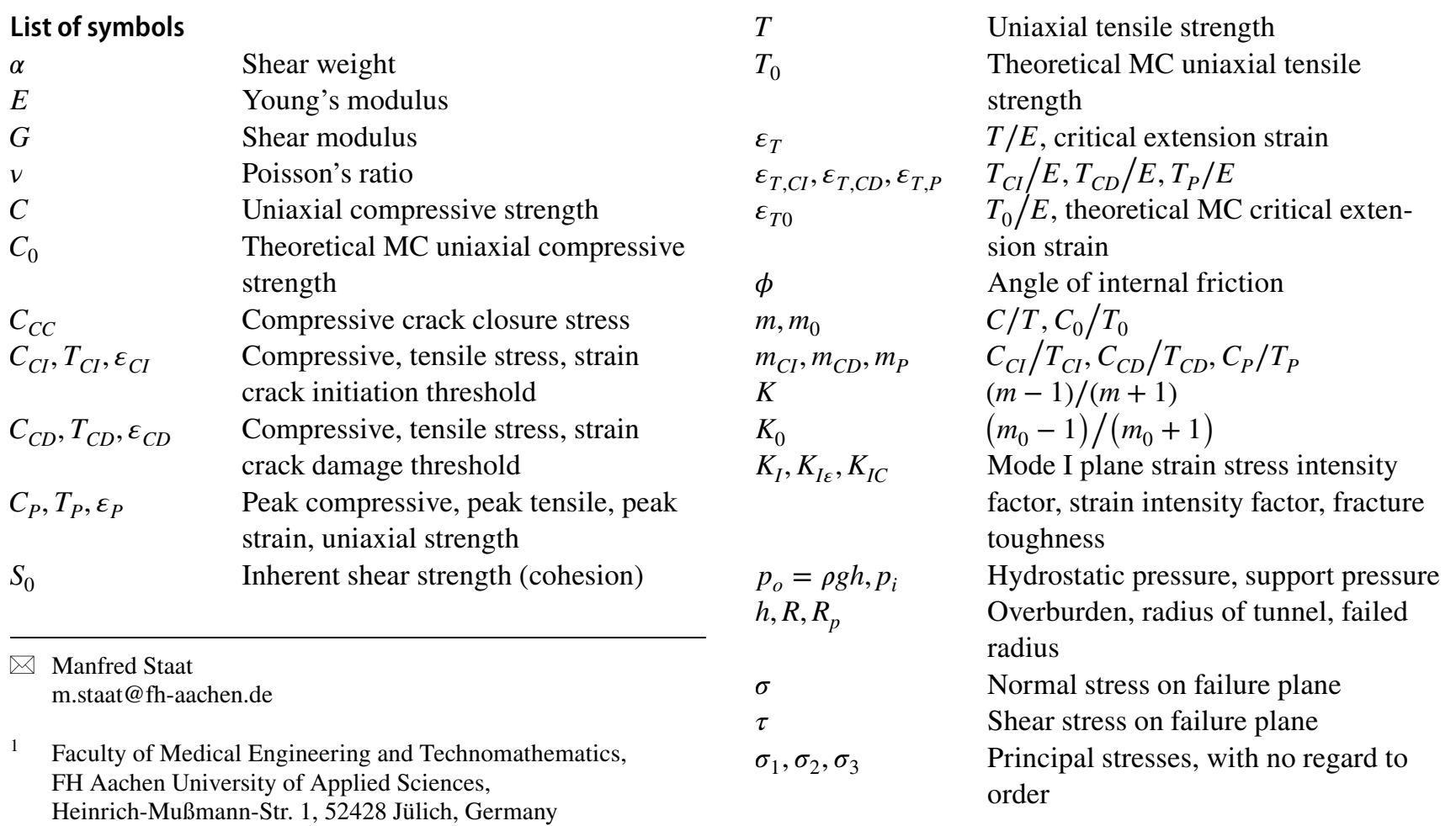




$\begin{array}{ll}\sigma_{I}, \sigma_{I I}, \sigma_{I I I} & \begin{array}{l}\text { Major, intermediate, minor principal } \\ \text { stresses }\end{array} \\ \varepsilon_{1}, \varepsilon_{2}, \varepsilon_{3} & \begin{array}{l}\text { Principal strains, with no regard to } \\ \text { order }\end{array} \\ \varepsilon_{I}, \varepsilon_{I I}, \varepsilon_{I I I} & \begin{array}{l}\text { Major, intermediate, minor principal } \\ \text { strains }\end{array} \\ \gamma_{i j} & \text { Principal shear in plane of } \varepsilon_{k}, k \neq i, j \\ \tau_{i j} & \begin{array}{l}\text { Principal shear stress in plane of } \sigma_{k}, \\ k \neq i, j\end{array} \\ \varepsilon_{e q}^{*}, \sigma_{e q}^{*} & \text { Equivalent strain, stress referred to } T \\ \varepsilon_{e q}, \sigma_{e q} & \text { Equivalent strain, stress referred to } C \\ E E, S E, M C, R, V & \begin{array}{l}\text { Enriched extension strain, simple } \\ \text { extension strain, Mohr-Coulomb, }\end{array} \\ \rho & \text { Rankine, de Saint Venant } \\ & \text { (Volumetric mass) density }\end{array}$

Abbreviations

$\begin{array}{ll}\text { AE } & \text { Acoustic emission } \\ \text { BTS } & \text { Brazilian tensile strength } \\ \text { CC, CI, CD } & \text { Crack closure, initiation, damage } \\ \text { CP } & \text { Peak stress } \\ \text { MC } & \text { Mohr-Coulomb } \\ \text { pp } & \text { Perfectly plastic } \\ \text { SD } & \text { Strength-differential } \\ \text { UCS } & \text { Uniaxial compressive peak strength } \\ \text { UTS } & \text { Uniaxial tensile peak strength } \\ \text { 2D, 3D } & \text { Two-dimensional (biaxial), three- } \\ & \text { dimensional (triaxial) }\end{array}$

\section{Introduction}

In uniaxial compression tests, axial splitting and lateral extension strains are observed in rock and in concrete. These splitting areas carry no macroscopic stress if the confinement effect is avoided by lubrication, low friction platens, or brush platens. Biaxial compression tests of rock show spalling in the stress free planes normal to the unconfined axis (Garg et al. 2018) or weakly pressure loaded planes. Similar spalling is often observed in deep underground mines in form of layers of parallel fractures formed around excavations. All these extension fractures are formed parallel to the direction of the major compressive stress and perpendicular to the minor stress, which could be zero or even compression. Extension fractures ('tensile' fractures formed under a compressive stress field) are the most common in deep mines (Stacey et al. 2003b; Barton and Shen 2017). They are formed by in induced 'tension', but within a wholly compressive stress field. It is difficult, if not impossible, to explain extension fracture on unconfined or weakly confined planes in rock by phenomenological stress failure criteria such as Mohr-Coulomb (MC) (Coulomb 1773; Mohr 1900; Nádai
1950), Griffith (Brace 1960), or Hoek-Brown (Hoek and Brown 1980) including their modifications and several other criteria. These criteria are based on major and minor stress and their difference proposes maximum shear stress to cause failure in contrast to the strongly tensile nature of extension fracture. The dominant fracture behavior of specimen in triaxial compression tests changes from shear to extension as the ductility of the samples decreases, controlled by lithology (Griggs and Handin 1960).

Experiments have confirmed that splitting parallel to the direction of maximum compression is the principal mode of macroscopic fracture in brittle rock (Fairhurst and Cook 1966). One possible way to explain these extension fractures uses the existence or creation of micro cracks, which evolve to macroscopic fractures. The most common types of failure patterns that were evident in 100 uniaxial compression tests were shearing along a particular plane and axial splitting and these failure patterns were related to the crack propagation direction and the spatial distribution of the relatively weaker zones. The extension fracture in form of axial cracking was more serious, because it occurred at lowest ultimate compressive strength compared to shearing along a single planetype failure at considerably higher stress for fine grained sandstone (Chakraborty et al. 2019). Extension fracture has been considered as a mystery in Kuijpers (2000) and a twostage fracture process is suggested as a possible explanation.

The extension strain criterion is found to be a more direct and simple explanation of tensile-type fractures on unconfined or weakly confined sections. Under compression, the Poisson effect produces extension strains in transverse direction and it is postulated that the extension strain leads to separation fracture similarly to tensile stress. The criterion accounts for all three stresses and predicts "tensile" fracture by extension strain even in cases that all three stresses are compressive. It was presented as a fracture initiation criterion under the "paradox" fracture of seemingly hard rock under low stress conditions, which often occurs near excavation boundaries (Stacey 1981; Wesseloo and Stacey 2016). Extension strain is used to explain slope failure in open pits (Stacey et al. 2003a; Al Mandalawi et al. 2020) and pillar failures during mining production (Rahjoo et al. 2016). The observation that tunnel spalling often starts when the tangential stress reaches a typical crack initiation level of $40 \%$ of the ultimate compressive strength has been seen as indicator to use the simple extension strain criterion (Barton and Shen 2017; Shen and Barton 2018). This is affected by a choice of the critical strain value, where the simple extension strain criterion corresponds to the crack initiation threshold in uniaxial compression tests (Stacey 1981). However, different choices are equally possible. The simple extension strain criterion has been derived independently with a critical strain value corresponding to the tensile stress in uniaxial compression with peak stress (Beierlein 1985). 
A statistical evaluation of the results of ten laboratory compression tests on Äspö diorite showed that any of five strain-based methods, including the simple extension strain criterion, provided statistically accurate predictions of the onset of cracking (Nicksiar and Martin 2012). The simple extension strain criterion with critical strain data from Stacey (1981) seems promising to explain crack initiation and propagation in the Brazilian test ( $\mathrm{Li}$ and Wong 2013). Uniaxial compression, triaxial compression, and Brazilian indirect tension tests were conducted on several kinds of rock, showing nearly the same value of critical principal tensile $^{1}$ strain at peak stress (Fujii et al. 1998). This is different from Stacey's crack initiation concept. Several laboratory tests, in situ, and numerical studies support the simple extension strain criterion and the reader should see (Wesseloo and Stacey 2016) for the detailed discussion of a number of references. Extension strain and the simple extension strain criterion denoted that limiting tensile strain criterion has been considered independently in Burzyński (1929) and for failure of concrete (Robinson 1967; Carino and Slate 1976) and ceramics (Beierlein 1985).

In a pressure chamber experiment, Nobel laureate Percy W. Bridgman observed a "pinching off" on the unloaded plane under equibiaxial pressure, which became known as Bridgman's paradox (Bridgman 1912). The same failure is observed as disking in deep vertical boreholes. Bridgman suggested that the pinching off could be explained by extension strain (Bridgman 1938). However, this has been controversial since. It is still an open question and debate if an extension strain criterion can be safely used for engineering decisions. It is pointed out in Jager and Ryder (2002) that the simple extension strain hypothesis predicts a halving of the strength in equibiaxial compression and recommend "... the extension strain hypothesis has little connection with reality, and in fact (at least in its present form) should not be used" [cited after (Wesseloo and Stacey 2016) and (Sengani 2020)]. Some deficiencies of the simple extension strain criterion are discussed and improvements are suggested by Rahjoo et al. 2016. Other authors, however, find that the simple extension strain criterion predicts typical rock failure quantitatively more realistically than, for example, the MC criterion (Barton and Shen 2018; Barton 2020). The stress concentration of in situ brittle rock mass caused by excavation results in localized damage evolution parallel to the free face. The failure mode of surface instability presents a transition from brittle to ductile behavior with the increase of distance from the surface to depth. It is modeled in $\mathrm{Li}$ et al.

\footnotetext{
${ }^{1}$ Extension and tensile strain are used for the same criterion in e.g. ( $\mathrm{Li}$ and Wong 2013). However, in this article, extension strain refers to the simple and to the enriched strain criterion, while tensile strain refers to such strain criteria that are not considered in detail here.
}

(2020) by the transition from the simple extension strain criterion to the MC criterion.

To answer the question if an extension strain criterion is applicable, an analytical approach is used assuming isotropic brittle rock. The focus is on the main representative criterion, disregarding the many different strain criteria proposed in the literature (Heidarzadeh et al. 2021). The simple extension strain criterion in Stacey (1981) or independently derived in Burzyński (1928) and Beierlein (1985) is mapped into stress and strain space and then compared with the established MC criterion to show that the simple extension strain criterion is too restrictive in biaxial compression and unsafe in biaxial tension. These problems are removed with a shear enrichment of the extension strain criterion, which has the same failure envelope as the MC criterion, but predicts extension failure. The enriched extension strain criterion is developed for different stages of crack damage evolution and corresponding characteristic strength thresholds. Therefore, the discussion is completed with the problems and choices of material data and considers the failure stages of crack damage in rocks. Finally, some analytical and numerical solutions of typical problems show the improvement, which is achieved by the enriched extension strain criterion.

\section{Two extension strain criteria}

\subsection{The Simple Extension Strain Criterion}

In isotropic material, stress $\sigma_{i j}$ and strain $\varepsilon_{i j}$ have the same principal axes with principal stresses $\sigma_{1}, \sigma_{2}, \sigma_{3}$ and principal strains $\varepsilon_{1}, \varepsilon_{2}, \varepsilon_{3}$ with no regard to order. If order is relevant, the principal stress indices are written, such that $\sigma_{I} \geq \sigma_{I I} \geq \sigma_{I I I}$. The largest principal strain (major strain) $\varepsilon_{I}$ occurs in the direction of the largest principal stress (major stress) $\sigma_{I}$, so that $\varepsilon_{I} \geq \varepsilon_{I I} \geq \varepsilon_{I I I}$. Here, the total stress is considered, although this can only be calculated up to an unknown self-equilibrated stress. ${ }^{2}$ In fact, the residual stress is in equilibrium with the zero stress and this zero stress can be added to any load case without changing the equilibrium. On the other hand, the total observable strain can be zero, but still lead to failure. Hence, it cannot be used in a failure criterion. The total strain includes strains in the structure due to thermal gradients, swelling, shrinkage, inelastic deformation, or phase changes. The strain criteria are based on the strain calculated from the total stress using Hooke's law.

\footnotetext{
${ }^{2}$ Residual stress can cause premature failure of brittle material, but it is no problem for ductile materials, because residual stress does not cause plastic collapse. This theorem of limit analysis has been demonstrated experimentally in (Maier-Leibnitz 1928).
} 


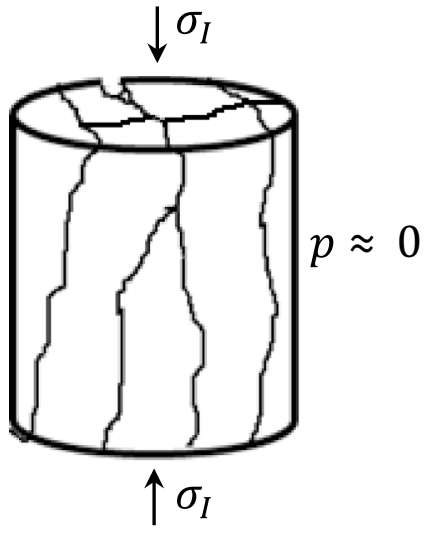

(a)

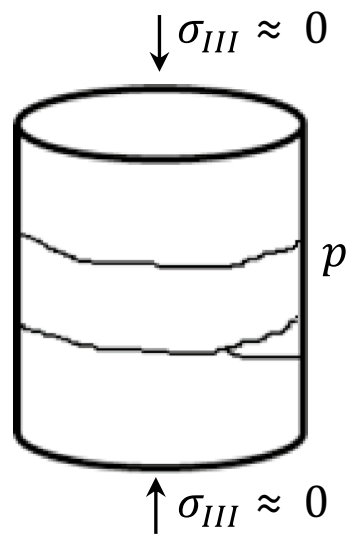

(b)

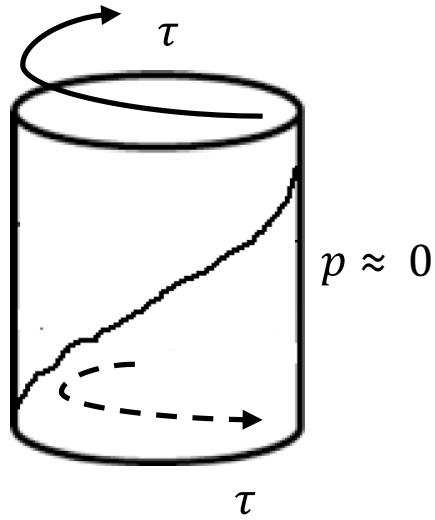

(c)
Fig. 1 Failure of a cylinder in its unloaded planes by a axial splitting under uniaxial compression $\left(\sigma_{\mathrm{I}}>0\right.$ and low or no confinement $\sigma_{\mathrm{II}}=\sigma_{\mathrm{III}}=p \approx 0$ ), $\mathbf{b}$ disking (cross-sectional splitting, pinching off)

Thus, thermal strains or other strain incompatibilities are taken into account if they cause residual stresses.

For rock and other brittle materials, it has been suggested that observed damage and final fracture on planes with least stress are caused by the most negative (extension) strain (Carino and Slate 1976; Stacey 1981; Beierlein 1985; Louchnikov 2011; Eyre and Nasreddin 2013; Wesseloo and Stacey 2016; Barton and Shen 2018; Al Mandalawi et al. 2020). The equivalent strain of the simple extension strain criterion is the absolute value of the most negative strain,

$$
\begin{aligned}
\varepsilon_{\mathrm{eq}, \mathrm{SE}}^{*}= & \max \left\{-\varepsilon_{1},-\varepsilon_{2},-\varepsilon_{3}\right\}=-\varepsilon_{\mathrm{III}} \\
= & \max \left\{\frac{v}{E}\left(\sigma_{2}+\sigma_{3}\right)-\frac{\sigma_{1}}{E}, \frac{v}{E}\left(\sigma_{3}+\sigma_{1}\right)\right. \\
& \left.-\frac{\sigma_{2}}{E}, \frac{v}{E}\left(\sigma_{1}+\sigma_{2}\right)-\frac{\sigma_{3}}{E}\right\} \\
= & \frac{v}{E}\left(\sigma_{I}+\sigma_{\mathrm{II}}\right)-\frac{\sigma_{\mathrm{III}}}{E} \leq \varepsilon_{T},
\end{aligned}
$$

where $\varepsilon_{T}>0$ is a critical extension strain and tension with $\varepsilon_{\mathrm{III}}<0$ and $-\sigma_{\mathrm{III}} \geq \sigma_{\mathrm{I}} \geq \sigma_{\mathrm{II}} \geq 0$ is assumed. In plane strain, the Young's modulus $E$ should be replaced by $E /\left(1-v^{2}\right)$ in the 2D version of (1) (Barton and Shen 2018). In addition, the Poisson's ratio $v$ needs to be replaced by $v /(1-v)$ in this case.

The simple extension strain criterion predicts the critical point (hot spot) at which fracture is to be expected from the negative minor strain $\varepsilon_{\mathrm{III}}$. The inequality shows that for $-\sigma_{\text {III }}>v\left(\sigma_{\mathrm{I}}+\sigma_{\mathrm{II}}\right)$, extension (negative strain) causing extension fracture can still occur if all stresses are compressive (positive). This would, e.g., occur in a confined compression test. Since the magnitude of the strain depends on all three principal stresses, the effect of the intermediate principal stress $\sigma_{\mathrm{II}}$ is automatically taken into account. The most negative under equibiaxial compression $\left(\sigma_{\mathrm{I}}=\sigma_{\mathrm{II}}=p>0\right.$, and low or no confinement $\sigma_{\mathrm{III}} \approx 0$ ), and $\mathbf{c}$ spiral fracture under torsion (pure shear $\tau$ and low or no confinement $\sigma_{\mathrm{II}}=p \approx 0$ )

(extension) strain criterion thus overcomes the problem of neglected intermediate principal stress associated with the Mohr-Coulomb criterion (Coulomb 1773), the Griffith fracture criterion (Griffith 1924), and the Hoek-Brown criterion (Hoek and Brown 1980). The Mohr-Coulomb criterion is too conservative, because it neglects the significant strengthening effect of the mean principal stress (Ewy 1998). Under hydrostatic pressure, all strains are positive and no failure can occur; under isostatic tension, all stresses are negative and failure can happen.

Zero principal stress in a plane does not imply zero principal strain normal to the plane with surprising consequences. Brittle geomaterials and concrete in uniaxial compression and in biaxial compression show rupture in planes with zero confinement stress, as shown in Fig. 1. From the stress point of view, this is unexpected. These planes are normal to the direction of the extension strain caused by the Poisson effect. If the stiffness reduction by damage is neglected and Hooke's law is assumed until fracture Eq. (1) is equivalent to the criterion based on the equivalent tensile stress (Burzyński 1929; Brown and Trollope 1967)

$$
\begin{aligned}
\sigma_{\mathrm{eq}, \mathrm{SE}}^{*} & =\varepsilon_{\mathrm{eq}, \mathrm{SE}}^{*} E=\max \left\{-\varepsilon_{1},-\varepsilon_{2},-\varepsilon_{3}\right\} E=-\varepsilon_{\mathrm{III}} E \\
& =\max \left\{v\left(\sigma_{2}+\sigma_{3}\right)-\sigma_{1}, v\left(\sigma_{3}+\sigma_{1}\right)-\sigma_{2}, v\left(\sigma_{1}+\sigma_{2}\right)-\sigma_{3}\right\} \\
& =v\left(\sigma_{\mathrm{I}}+\sigma_{\mathrm{II}}\right)-\sigma_{\mathrm{III}} \leq T .
\end{aligned}
$$

It is usually assumed that the ultimate strength in uniaxial tension $T$ can be used here. Different from other authors, only positive material constants $(T>0)$ are used.

In uniaxial tension, $\sigma_{\mathrm{III}}=-T, \sigma_{\mathrm{I}}=\sigma_{\mathrm{II}}=0$, so that the critical extension strain is $\varepsilon_{T}=-\varepsilon_{\mathrm{III}}=T / E$ and the major 
Table 1 SD effect for intact rock; mean values of Poisson's ratio $v$, uniaxial tensile strength Tand compressive strength $C$ from (Panthee et al. 2016); $T / C=1 / m$ calculated

\begin{tabular}{lllllllll}
\hline Lithology & Marble & $\begin{array}{l}\text { Garnetifer- } \\
\text { ous schist }\end{array}$ & $\begin{array}{l}\text { Psammitic } \\
\text { schist }\end{array}$ & $\begin{array}{l}\text { Schistose } \\
\text { quartzite }\end{array}$ & Quartzite & Phyllite & $\begin{array}{l}\text { Siliceous } \\
\text { dolomite }\end{array}$ & Slate \\
\hline$v$ & 0.18 & 0.16 & 0.20 & 0.17 & 0.17 & 0.26 & 0.18 & 0.23 \\
$T / C=1 / m$ & 0.1 & 0.11 & 0.11 & 0.13 & 0.12 & 0.13 & 0.13 & 0.07 \\
$T(\mathrm{MPa})$ & 11.7 & 8.6 & 10.3 & 13.8 & 23.2 & 10.4 & 21.3 & 6.4 \\
$C(\mathrm{MPa})$ & 122 & 78 & 91 & 109 & 190 & 82 & 169 & 93 \\
\hline
\end{tabular}

strains are $\varepsilon_{\mathrm{I}}=\varepsilon_{\mathrm{II}}=v T / E$. Let $C$ denote the ultimate uniaxial compressive strength. In uniaxial compression, $\sigma_{\mathrm{I}}=C, \sigma_{\mathrm{II}}=\sigma_{\mathrm{III}}=0$, so that the critical extension strain $\varepsilon_{T}=-\varepsilon_{\mathrm{II}}=-\varepsilon_{\mathrm{III}}=-\nu C / E$ and the major strain $\varepsilon_{I}=C / E$ is in the load direction. In uniaxial compression, the specimen in Fig. 1a thickens radially and the extension strains $\varepsilon_{\mathrm{II}}=\varepsilon_{\mathrm{III}}=-\varepsilon_{T}$ explain the observed axial splitting at a critical strain limit in the unconfined planes (Kunz 2011). The most striking prediction of the simple extension strain criterion is the occurrence of an SD effect, also denoted strength asymmetry $0<T / C=v<0.5$, which excludes (ductile) even materials with symmetric strength $T / C=1$.

In biaxial compression tests, the specimen in Fig. $1 \mathrm{~b}$ elongates axially and cracks in the cross section (normal to the axis) have to be expected to occur at the same critical extension strain limit. The effect has already been shown in classic experiments (Föppl 1900; Bridgman 1912) and is since used as alternative tension test. The effect has been observed and explained for concrete in Robinson (1967). This splitting of stress free planes is observed as disking of deep drill cores and the contribution of flaws is discussed in Huang et al. (2016). The rate of unloading seems to determine if the fracture is extension or sliding, so that the extension strain may not explain all highly dynamic failure processes (Bauch and Lempp 2004). A fracture mechanics view is that under compression, wing cracks develop at the tips of existing sliding flaws and form crack patterns, which fail under extension (Scholz et al. 1986).

Table 1 shows that the Poisson effect strongly contributes to the SD effect in brittle material like intact rock. A material with $T / C=1$ and $T / C=0$ is considered as perfectly ductile and perfectly brittle, respectively. The ratio $T / C=0.5$ is proposed as a limit between ductile and brittle behavior (Christensen 2013). A relation between Poisson's ratio and the SD effect of the MC criterion has also been observed independently from the extension strain criterion in Baricco et al. (2009).

The Poisson effect is only a simple phenomenological model. Compression caused splitting on unloaded planes in brittle material has been explained by tensile stress at in homogeneities of grains in rock matrix or by unstable micro-cracking and fracture mechanics using stress intensity factor (Horii and Nemat-Nasser 1986; Iskander and Shrive
2018). A numerical simulation (bonded disc model) is used in Diederichs (2003) to illustrate the generation of both grain scale tension and more regional tensile stress through heterogeneity of rock. Crack interaction occurs when a critical crack density is reached and marks the onset of true yield in these simulated specimens. The critical crack density, the onset of stress-strain non-linearity was shown to correspond to a consistent level of lateral extension strain. The important point here is that confinement dependency for crack interaction, and therefore for upper bound rock mass strength, is not the result of conventional sliding friction, but rather of the elastic generation of extension strain and tensile crack accumulation in which friction plays no part (Diederichs 2003). Damage evolution by initiation and growth of cracks occur below the macroscopic failure of rock, so that $C$ as a stress threshold and the use of Hooke's law have to be reconsidered in more detail in Sect. 3.2.1. It is observed in rock or shown in simulations with a bonded-particle model of concrete that in compression tests, the extension by the Poisson effect produces an order more cracks at lower strains compared with the direct extension in tensile tests (Ren et al. 2018). Therefore, the use of $T$ in Eq. (2) is not strictly justified and the critical tensile strain $\varepsilon_{T}=T / E$ may not hold precisely. Also, Table 1 shows that the measured values differ from the prediction $C=T / v$.

The simple extension strain criterion is shown in Fig. 2 for Poisson's ratio $v=0.25$ in comparison with other failure criteria with the SD effect, all for $T / C=0.25$. The classical Mohr-Coulomb (MC) criterion (de Coulomb 1776; Mohr 1900) for fracture of brittle material can be written with emphasis on the SD effect as equivalent stress (Labuz and Zang 2012),

$$
\begin{aligned}
\sigma_{\text {eq,MC }}= & \frac{m+1}{2} \max \left\{\left|\sigma_{1}-\sigma_{2}\right|-K\left(\sigma_{1}+\sigma_{2}\right),\left|\sigma_{1}-\sigma_{3}\right|\right. \\
& \left.-K\left(\sigma_{1}+\sigma_{3}\right),\left|\sigma_{2}-\sigma_{3}\right|-K\left(\sigma_{2}+\sigma_{3}\right)\right\} \leq C, \\
K= & \frac{m-1}{m+1}=\frac{C-T}{C+T}, \quad m=\frac{C}{T} .
\end{aligned}
$$

The MC criterion is based on shear stress and sliding friction and is popular as failure criterion of rocks. $\sigma_{1}, \sigma_{2}, \sigma_{3}$ represent the principal stresses with six 


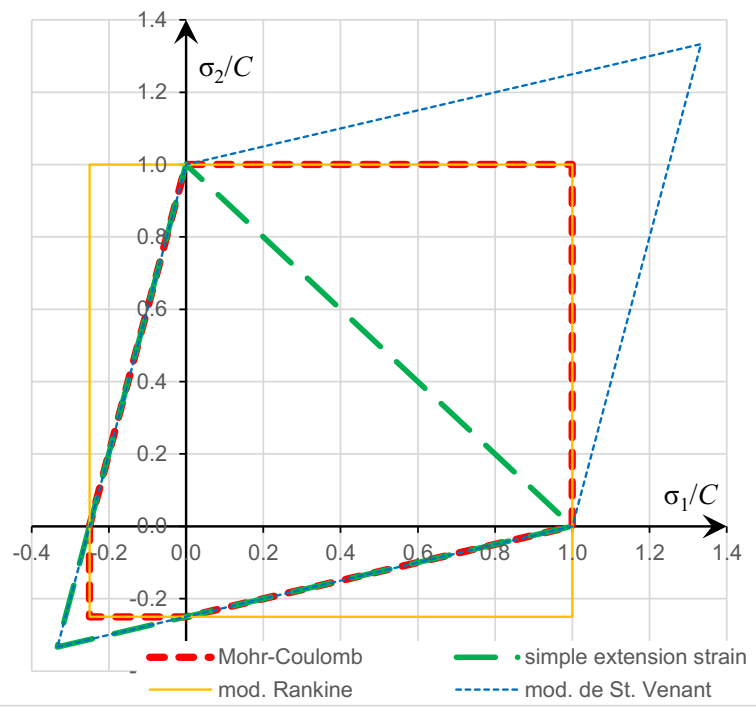

(a) Principal stress space (strength diagram)

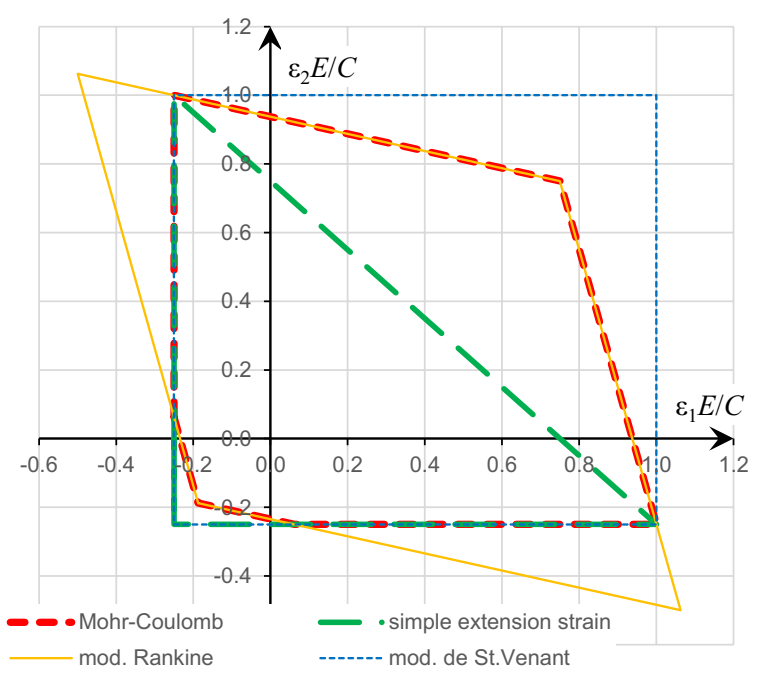

(b) Principal strain space (forming limit diagram)

Fig. 2 Comparison of failure theories for SD effect in geomaterials with $T=v C$ for $v=0.25, m=1 / v=4$ (colors in online publication)

permutations of the order. Therefore, the MC yield surface is a hexagonal conical prism with the inclination angle $K$ of the conical surface in 3D space of principal stress. In 2D space of principal stress, it is a cross section of the conical prism shown as an irregular hexagon in Fig. 2a. In the ductile limit $m=1$, the SD effect disappears and the Tresca maximum shear stress criterion $m=1 \quad \sigma_{\mathrm{eq}, T}^{*} \max \left(\left|\sigma_{1}-\sigma_{2}\right|,\left|\sigma_{2}-\sigma_{3}\right|,\left|\sigma_{3}-\sigma_{1}\right|\right)=\left|\sigma_{\mathrm{III}}-\sigma_{\mathrm{I}}\right| \leq T$ is assumed. This failure criterion for even materials without SD effect contains only one material constant which is typically the tensile strength $T$.

For additional comparison, Rankine's maximum stress criterion is modified to include the SD effect for $\sigma_{\mathrm{I}} \geq 0 \geq \sigma_{\mathrm{III}}$

$\sigma_{\mathrm{eq}, R}^{*}=-\sigma_{\mathrm{III}} \leq T, \quad \sigma_{\mathrm{eq}, R}=\sigma_{\mathrm{I}} \leq C$.

Similarly, the de Saint Venant maximum strain criterion can be modified to include the SD effect for $\varepsilon_{\mathrm{I}} \geq 0 \geq \varepsilon_{\mathrm{III}}$

$\varepsilon_{\mathrm{eq}, V}^{*}=-\varepsilon_{\mathrm{III}} \leq T / E, \quad \varepsilon_{\mathrm{eq}, V}=\varepsilon_{I} \leq C / E$.

The same properties are observed for the above piecewise linear criteria plotted in 2D stress and strain space, Fig. 2a, b. All criteria have the same number of corresponding corners in both spaces. However, corners on the compressive part of the stress axes do not transfer to corners on strain axes, because uniaxial stress correlates to triaxial strain (the critical $\varepsilon_{T}=T / E$ is not measured in uniaxial strain, Table 2). This is the reason why extension strain occurs in compressive stress. Under dominating shear (2nd and 4th quadrant), the simple extension strain criterion coincides with the MC criterion for shear failure (Beierlein 1985; Eyre and Nasreddin 2013; Kolupaev 2018).

Let $\mathrm{AT}$ and $\mathrm{AC}$ be the equibiaxial strength in tension and compression, respectively. For concrete AT $\approx T$ and $\mathrm{AC} \approx 1.16 C$ is found in Kupfer et al. (1969), also for rock typically $\mathrm{AT} \approx T$ and $\mathrm{AC} \approx C$. The $\mathrm{MC}$ criterion predicts $\mathrm{AT}=T$ and $\mathrm{AC}=C$, and can be used to discriminate between the criteria in biaxial tests. In biaxial tension (3rd quadrant), the simple extension strain criterion is unsafe with respect to the MC criterion. Under biaxial compression (1st quadrant), it is overly conservative (Beierlein 1985; Kolupaev 2018); the stress and strain limit is only half the value of the value from the $\mathrm{MC}$ criterion under equibiaxial compression as pointed out in Jager and Ryder (2002). For $T / C \rightarrow 0$, all criteria tend to the Rankine and the de Saint Venant failure envelope with the exception of the simple extension strain criterion which allows only the fixed half value in equibiaxial stress and strain. For all ratios $T / C$, the simple extension strain criterion is represented in the 1st quadrant (compression) by the same diagonal line between the points $(0,1)$ and $(1,0)$ in the normalized 2D principal stress space, Fig. 2a. The diagonal connects the points $(-v, 1)$ and $(1,-v)$ in the normalized 2D principal strain space, Fig. $2 b$. Therefore, in agreement with Jager and Ryder (2002), the use of the simple extension strain criterion is not recommended and a new enriched strain criterion is proposed in the next section. 
Table 2 Probable failure modes predicted on the basis of the contribution of the chosen shear weight $\alpha=2 v$ to the factor of equivalent stress and strain for some tests

\begin{tabular}{|c|c|c|c|c|c|}
\hline Test & Uniaxial tension & $\begin{array}{l}\text { Equibiaxial compres- } \\
\text { sion }\end{array}$ & Uniaxial compression & Equibiaxial tension & Pure shear \\
\hline Stress state & $\sigma_{\mathrm{I}}=\sigma_{\mathrm{II}}=0, \sigma_{\mathrm{III}}=-T$ & $\sigma_{\mathrm{I}}=\sigma_{\mathrm{II}}=C, \sigma_{\mathrm{III}}=0$ & $\sigma_{\mathrm{I}}=C, \sigma_{\mathrm{II}}=\sigma_{\mathrm{III}}=0$ & $\sigma_{\mathrm{I}}=0, \sigma_{\mathrm{II}}=\sigma_{\mathrm{III}}=-T$ & $\begin{array}{c}\sigma_{\mathrm{I}}=T, \sigma_{\mathrm{II}}=0 \\
\quad, \sigma_{\mathrm{III}}=-T\end{array}$ \\
\hline $\begin{array}{l}\text { Equivalent stress } \\
\text { Eq. (7) }\end{array}$ & $T$ & $2 v C$ & $\left(v+\frac{\alpha}{2}\right) C$ & $\left(1-v+\frac{\alpha}{2}\right) T$ & $\left(1+v+\frac{\alpha}{2}\right) T$ \\
\hline Strain state & $\varepsilon_{\mathrm{I}}=\varepsilon_{\mathrm{II}}=\nu \frac{T}{E} \varepsilon_{\mathrm{III}}=-\frac{T}{E}$ & $\begin{array}{c}\varepsilon_{\mathrm{I}}=\varepsilon_{\mathrm{II}}=\frac{c}{E_{C}} \\
\quad, \varepsilon_{\mathrm{III}}=-v \frac{{ }^{2}}{E}\end{array}$ & 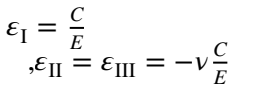 & $\begin{array}{l}\varepsilon_{\mathrm{I}}=v \frac{T}{E} \\
\quad, \varepsilon_{\mathrm{II}}=\varepsilon_{\mathrm{III}}=-\frac{T}{E}\end{array}$ & $\varepsilon_{\mathrm{I}}=\frac{T}{E}, \varepsilon_{\mathrm{II}}=0, \varepsilon_{\mathrm{III}}=-\frac{T}{E}$ \\
\hline $\begin{array}{l}\text { Equivalent strain } \\
\text { Eq. (6) }\end{array}$ & $\frac{T}{E}$ & $2 v \frac{C}{E}$ & $\left(v+\frac{\alpha}{2}\right) \frac{C}{E}$ & $\left(1-v+\frac{\alpha}{2}\right) \frac{T}{E}$ & $\left(1+v+\frac{\alpha}{2}\right) \frac{T}{E}$ \\
\hline $\begin{array}{l}\text { Predicted failure } \\
\text { mode }\end{array}$ & Extension & Extension & Extension and shear & Extension (and shear) & Extension dominant \\
\hline Failure modes & $\begin{array}{l}\text { Separation of cross } \\
\text { section }\end{array}$ & Figures 1a, 3a & Figures $1 b, 3 b$ & Difficult test & Figure $1 \mathrm{c}$ \\
\hline
\end{tabular}

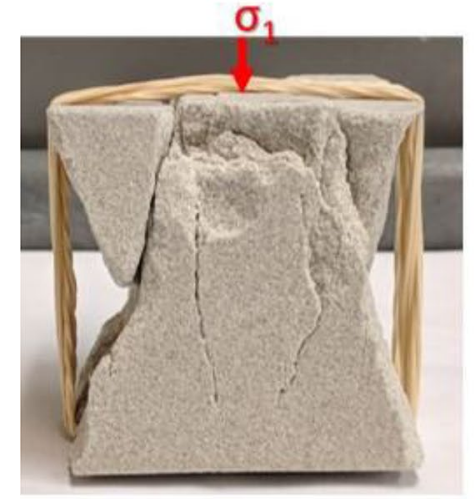

(a)

Fig. 3 Failure of a cube of Berea sandstone in its unloaded planes: a by axial splitting with shear contributions under uniaxial compression $\left(\sigma_{\mathrm{II}}=\sigma_{\mathrm{III}}=0\right)$; b by disking (cross-sectional splitting) under

\subsection{An Enriched Extension Strain Criterion}

The most simple extension strain criterion is on the same failure envelope as the widely accepted MC criterion (internal friction theory) in plane shear stress (2nd and 4th quadrant in Fig. 2); in other words, the criterion is quite useful for shear problems. It has problems for biaxial conditions being unsafe in tension (3rd quadrant) and overly conservative in compression (1st quadrant).

Some shearing failure contributions are sometimes observed in connection with extension fractures in uniaxial and polyaxial testing conditions (Fig. 3). Therefore, it is

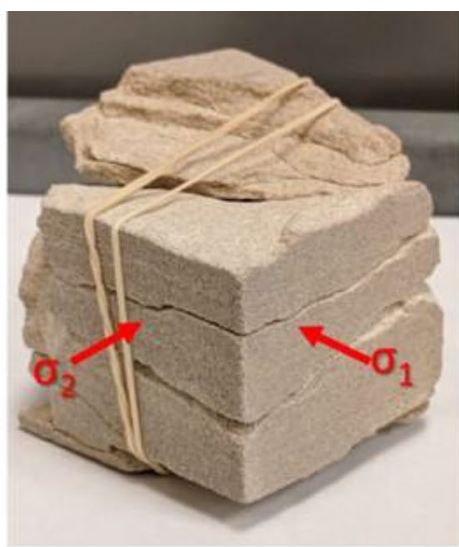

(b)

equibiaxial compression $\left(\sigma_{\mathrm{III}}=0\right)$ with proportional load path, from (Garg et al. 2018) with permission of the author and American Rock Mechanics Association (ARMA). (colors in online publication)

suggested in Nadler (1989) to add some shear to Eq. (1) with an empirical shear weight $\alpha$. This suggestion has been implemented for ceramics in Jakel (1993) with the choice of the maximum principal shear strain $\gamma_{\text {III }}=\left|\varepsilon_{\mathrm{I}}-\varepsilon_{\mathrm{II}}\right| / 2$ (maximum principal shear stress ${ }^{3} \tau_{\mathrm{III}}=\left|\sigma_{\mathrm{I}}-\sigma_{\mathrm{II}}\right| / 2=G \gamma_{12}$ with shearing modulus $G=E /[2(1+v)])$ in the plane normal to the (negative) minor principal strain $\varepsilon_{\text {III }}$ (for isotropic material, the minor principal stress $\sigma_{\mathrm{II}}$ appears in the same plane). This leads to the equivalent strain as follows:

\footnotetext{
${ }^{3}$ Twice the shear stress $\sigma_{I}-\sigma_{I I}$ is also denoted differential stress.
} 


$$
\begin{aligned}
\varepsilon_{\mathrm{eq}, \mathrm{EE}}^{*}= & \max \left\{\frac{\alpha}{4(1+v)}\left|\varepsilon_{2}-\varepsilon_{3}\right|-\varepsilon_{1}, \frac{\alpha}{4(1+v)}\left|\varepsilon_{3}-\varepsilon_{1}\right|\right. \\
& \left.-\varepsilon_{2}, \frac{\alpha}{4(1+v)}\left|\varepsilon_{1}-\varepsilon_{2}\right|-\varepsilon_{3}\right\} \\
= & \frac{\alpha}{4(1+v)}\left|\varepsilon_{\mathrm{I}}-\varepsilon_{\mathrm{II}}\right|-\varepsilon_{\mathrm{III}} \leq T / E .
\end{aligned}
$$

The equivalent stress of the in-plane enriched extension strain criterion is

$$
\begin{aligned}
\sigma_{\text {eq,EE }}^{*}= & \varepsilon_{\text {eq,EE }}^{*} E \\
= & \max \left\{v\left(\sigma_{2}+\sigma_{3}\right)-\sigma_{1}+\frac{\alpha}{2}\left|\sigma_{2}-\sigma_{3}\right|,\right. \\
& v\left(\sigma_{3}+\sigma_{1}\right)-\sigma_{2}+\frac{\alpha}{2}\left|\sigma_{3}-\sigma_{1}\right|, \\
& \left.v\left(\sigma_{1}+\sigma_{2}\right)-\sigma_{3}+\frac{\alpha}{2}\left|\sigma_{1}-\sigma_{2}\right|\right\} \\
= & \sigma=v\left(\sigma_{\mathrm{I}}+\sigma_{\mathrm{II}}\right)-\sigma_{\mathrm{III}}+\frac{\alpha}{2}\left|\sigma_{\mathrm{I}}-\sigma_{\mathrm{II}}\right| \leq T .
\end{aligned}
$$

The shear weight $\alpha$ can be determined from the SD effect measured in uniaxial tests. In uniaxial tension test $\sigma_{\mathrm{III}}=-T$, $\sigma_{\mathrm{I}}=\sigma_{\mathrm{II}}=0$, so that the critical strain is $\varepsilon_{T}=-\varepsilon_{\mathrm{III}}=T / E$. In uniaxial compression test $\sigma_{\mathrm{I}}=C, \sigma_{\mathrm{II}}=\sigma_{\mathrm{III}}=0$, the critical strain is $\varepsilon_{T}=(v+\alpha / 2) C / E$. This gives,

$\frac{T}{C}=\frac{1}{m}=v+\frac{\alpha}{2}$

so that $\alpha=2(T / C-v)$ for known Poisson's ratio $v$. The theoretical limit is $0 \leq \alpha \leq 2(1+v)$ (Jakel 1993).

In axisymmetric extension (equibiaxial tension test) $\sigma_{I I}=\sigma_{I I I}=-\mathrm{AT}, \sigma_{1}=0$, the critical strain is $\varepsilon_{\mathrm{AT}}=-\varepsilon_{\mathrm{II}}=-\varepsilon_{\mathrm{III}}=(1-v+\alpha / 2) \mathrm{AT} / E$. The ratio is $T / \mathrm{AT}=1-\nu+\alpha / 2$, so that the weight $\alpha$ can be found as $\alpha=2(T / \mathrm{AT}-1+v)$. In axisymmetric compression (equibiaxial compression test) $\sigma_{\mathrm{I}}=\sigma_{\mathrm{II}}=\mathrm{AC}, \sigma_{\mathrm{III}}=0$, the critical strain is $\varepsilon_{\mathrm{AC}}=-\varepsilon_{\mathrm{III}}=2 v \mathrm{AC} / E$. The ratio is $C / \mathrm{AC}=(v+\alpha / 2) / 2 v$, so that the weight $\alpha$ can be found as $\alpha=2 v(2 C / \mathrm{AC}-1)$. The $\mathrm{MC}$ criterion predicts $\mathrm{AT}=T$ and $\mathrm{AC}=C$, so that the enriched extension strain criterion assumes the MC criterion with the choice $\alpha=2 \nu$, $1 / m=T / C=2 \nu$ from Eq. (8) and $\varepsilon_{T}=T / E=2 \nu C / E$.

With the shear weight $\alpha=2 v$, the enriched extension strain criterion (6) is.

$$
\begin{aligned}
\varepsilon_{\mathrm{eq}, \mathrm{EE}}^{*} & =\frac{v}{2(1+v)}\left|\varepsilon_{\mathrm{I}}-\varepsilon_{\mathrm{II}}\right|-\varepsilon_{\mathrm{III}} \\
& =\frac{v}{E}\left(\sigma_{\mathrm{I}}+\sigma_{\mathrm{II}}\right)-\frac{\sigma_{\mathrm{III}}}{E}+v \frac{\left|\sigma_{\mathrm{I}}-\sigma_{\mathrm{II}}\right|}{E} \leq T / E .
\end{aligned}
$$

This is an equivalent strain calculated from three measured or computed principal strains and is not an actual strain that could be measured. Similarly, equivalent stress like $\sigma_{\text {eq,MC }}$ is calculated from the computed principal stress and is not an equilibrium stress. In this sense, we choose to replace $v$ in Eq. (9) by $1 /(2 \mathrm{~m})$, which is not understood as an elastic constant in Hooke's law (especially with regard to the data in Table 1). With the limit $C$ instead of $T$, the Eq. (6) reads,

$$
\begin{aligned}
\varepsilon_{\mathrm{eq}, \mathrm{EE}}^{*}= & \max \left\{\frac{1}{2(1+2 m)}\left|\varepsilon_{2}-\varepsilon_{3}\right|\right. \\
& -\varepsilon_{1}, \frac{1}{2(1+2 m)}\left|\varepsilon_{3}-\varepsilon_{1}\right| \\
& \left.-\varepsilon_{2}, \frac{1}{2(1+2 m)}\left|\varepsilon_{1}-\varepsilon_{2}\right|-\varepsilon_{3}\right\} \\
= & \frac{1}{2(1+2 m)}\left|\varepsilon_{\mathrm{I}}-\varepsilon_{\mathrm{II}}\right|-\varepsilon_{\mathrm{III}} \leq \varepsilon_{T}, \\
& \varepsilon_{T}=\frac{T}{E}=m \frac{C}{E}, \\
= & \varepsilon_{\mathrm{eq}, \mathrm{EE}}^{*} E m \\
= & \max \left\{\frac{1}{2}\left(\sigma_{2}+\sigma_{3}\right)-\sigma_{1} m\right. \\
& +\frac{1}{2}\left|\sigma_{2}-\sigma_{3}\right|, \frac{1}{2}\left(\sigma_{3}+\sigma_{1}\right)-\sigma_{2} m \\
& \left.+\frac{1}{2}\left|\sigma_{3}-\sigma_{1}\right|, \frac{1}{2}\left(\sigma_{1}+\sigma_{2}\right)-\sigma_{3} m+\frac{1}{2}\left|\sigma_{1}-\sigma_{2}\right|\right\} \\
= & \max \left\{\frac{1}{2}\left(\sigma_{\mathrm{I}}+\sigma_{\mathrm{II}}\right) \sigma_{\mathrm{III}} m+\frac{1}{2}\left|\sigma_{\mathrm{I}}-\sigma_{\mathrm{II}}\right|\right\} \\
= & \sigma_{\mathrm{I}}-\sigma_{\mathrm{III}} m \leq C .
\end{aligned}
$$

Then, the intermediate stress is not effective as consequence of the choice $m=1 /(2 v)$, because $\max \left\{\left(\sigma_{\mathrm{I}}+\sigma_{\mathrm{II}}\right) / 2-\sigma_{\mathrm{III}} m \pm\left(\sigma_{\mathrm{I}}-\sigma_{\mathrm{II}}\right) / 2\right\}$ $=\max \left\{\sigma_{\mathrm{I}}-\sigma_{\mathrm{III}} m, \sigma_{\mathrm{II}}-\sigma_{\mathrm{III}} m\right\}=\sigma_{\mathrm{I}}-\sigma_{\mathrm{III}} m \leq C$.

For comparison, let the maximum in the MC criterion (3) be assumed as,

$$
\begin{aligned}
\sigma_{\text {eq,MC }} & =\max \left\{ \pm \frac{m+1}{2}\left(\sigma_{\mathrm{III}}-\sigma_{\mathrm{I}}\right)-\frac{m-1}{2}\left(\sigma_{\mathrm{III}}+\sigma_{\mathrm{I}}\right)\right\} \\
& =\sigma_{\mathrm{I}}-\sigma_{\mathrm{III}} m \leq C .
\end{aligned}
$$

Thus, the enriched extension strain criterion and the MC criterion both read

$\sigma_{\mathrm{eq}, \mathrm{AU}}=\sigma_{\mathrm{I}}-\sigma_{\mathrm{III}} m=\sigma_{\mathrm{eq}, \mathrm{MC}} \leq C$.

Finally, it is observed that the MC and the enriched extension strain criterion are represented by the same curves in all quadrants in Fig. 4, so that they predict failure in the same hot spot of rock at the same load level. Under hydrostatic pressure, all stresses/strains are positive and no failure can occur. Under isostatic tension, all stresses/strains are negative and failure can happen. In Fig. 4a, a Rankine-like maximum absolute value stress criterion with SD effect is plotted in principal stress space for comparison, and in Fig. 4b, a de Saint Venant like maximum absolute value strain criterion with SD effect 


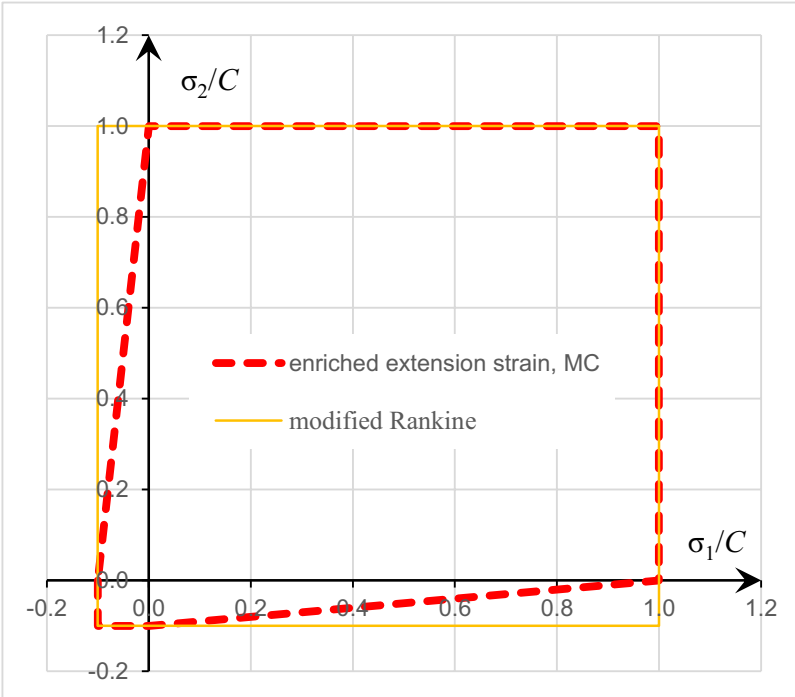

(a) Principal stress space (strength diagram)

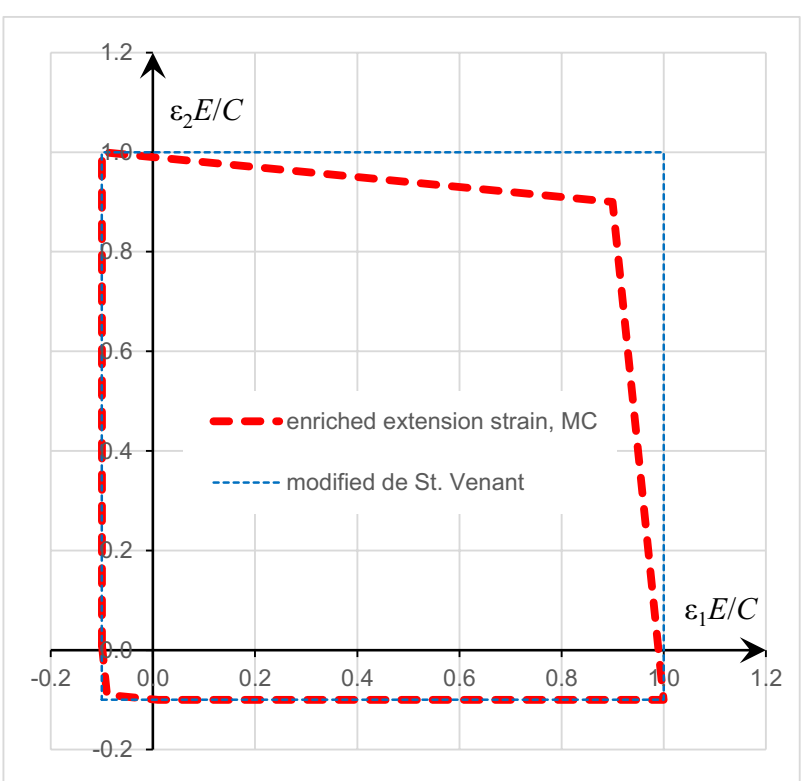

(b) Principal strain space (forming limit diagram)

Fig. 4 Comparison of failure theories for rocks with $T=C / m$ for $m=10$. The enriched extension strain theory is equivalent to the MC theory in this plot (colors in online publication)

is added in principal strain space. It is obvious that both maximum absolute value criteria with SD effect are unsafe. Particularly, the modified de Saint Venant maximum strain criterion is severely unsafe for biaxial tension and compression.

The idea to enrich the extension strain by shear is supported by the observation that the octahedral strain could be a better predictor than the extension strain (Kwaśniewski and Takahashi 2010). A comparison with the MC criterion has been made without deriving the enhanced tensile strain criterion in Eyre and Nasreddin (2013).
The free choice of the shear weight $\alpha$ allows a class of strain criteria, which are independent of the MC shear strength theory. The enriched extension strain criterion is different from the MC stress criterion, which is based on shear strength (Yu and Wang 2019). A major shear fracture at peak strength is not always observed (Wawersik and Fairhurst 1970). By comparing the shear weight $\alpha / 2$ with $v$ or $1+v$ as weights of the extensions in Table 2, we find that the enriched criterion typically predicts extension fractures parallel to the direction of the major compressive stress and perpendicular to the minor stress. Uniaxial tension produces the same deformation as equibiaxial compression and the same type of extension crack pattern leading to disking at different stress. Changing signs, uniaxial compression produces the same deformation as equibiaxial tension and the same type of crack pattern leading to axial splitting as the dominant failure mode in uniaxial compression which seems to be related with tests showing low failure loads (Basu et al. 2013; Chakraborty et al. 2019). A possible contribution of shear failure in uniaxial compression seems to coincide with apparent higher strength and may be a consequence of friction between load platens and specimen producing an inhomogeneous multiaxial stress state. Pure shear failure is dominated by extension failure in the plane of maximum extension strain and maximum tensile stress, as shown by the spiral fracture of concrete cylinders loaded in torsion (Fig. 1c), (Lilliu and van Mier 2001). Although the new extension strain criterion has been enriched by adding the weighted maximum principal shear strain, the expected direction of fracture is still predicted to be mostly orthogonal to the maximum extension strain.

The enriched extension strain criterion is proposed as a criterion, which has the same failure envelope as the MC criterion, but predicts the dominating extension failure modes. With this property, it is no more necessary to use the MC criterion and extension shear criterion separately for shear failure and tension failure, respectively, as done in a cellular automata to simulation ( $\mathrm{He}$ and $\mathrm{Li} 2010$ ). The properties collected for the MC criterion in $\mathrm{Yu}$ et al. (2009) can be cited for the enriched extension strain criterion: it accounts for the strength differential effect, the normal stress, a single-shear stress, and the hydrostatic stress, but neglects the effect of the intermediate principal stress, the intermediate principal shear stress, and the socalled twin-shear stresses. It is a lower bound of the many convex criteria proposed for geomaterials.

If plastic finite-element analysis should be an issue, the corners in the piecewise linearly defined MC criterion can be rounded to obtain well-defined derivatives for the computation of the plastic strain increments. Smoothing is achieved if Weibull statistics is applied to failure of brittle material (Jakel 1993). Several nonlinear 
Table 3 Estimated typical data $\phi, S_{0}, C, T, v$, and $E$ of rock mass (Hoek and Brown 1997)

\begin{tabular}{llll}
\hline & $\begin{array}{l}\text { Very good } \\
\text { quality, hard }\end{array}$ & Average quality & Very poor quality \\
\hline$\phi\left(^{\circ}\right)$ & 46 & 33 & 24 \\
$\phi_{\#}$ & 75.4 & 77.7 & 87.2 \\
$S_{0}(\mathrm{MPa})$ & 13 & 3.5 & 0.55 \\
$S_{\#}(\mathrm{MPa})$ & 3.5 & 0.7 & 0.02 \\
$C(\mathrm{MPa})$ & 54.8 & 13 & 1.7 \\
$C_{0}(\mathrm{MPa})$ & 64.4 & 12.9 & 1.69 \\
$T(\mathrm{MPa})$ & 0.9 & 0.15 & 0.01 \\
$T_{0}(\mathrm{MPa})$ & 10 & 3,8 & 0.71 \\
$m$ & 60.9 & 86.7 & 170 \\
$m_{0}$ & 6.4 & 3.39 & 2.38 \\
$v$ & 0.2 & 0.25 & 0.3 \\
$1 /(2 \nu)$ & 2.5 & 2 & 1.7 \\
$E(\mathrm{GPa})$ & 42 & 9 & 1.4 \\
$\varepsilon_{T}(\%)$ & 0.0021 & 0.0017 & 0.0007 \\
$\varepsilon_{T 0}(\%)$ & 0.024 & 0.042 & 0.051 \\
\hline
\end{tabular}

Calculated values $C_{0}, T_{0}, \phi_{\#}, S_{\#}, m, m_{0}, \varepsilon_{T}$, and $\varepsilon_{T 0}$

and smooth criteria have been proposed and tested on different materials as alternatives to the MC criterion (Burzyński 1928; Drucker and Prager 1952; Barsanescu et al. 2018; Wojciechowski 2018; Riyad et al. 2020). However, smoothing of the MC criterion is not necessary, since effective algorithms for plasticity with multiple yield planes have been developed (Clausen et al. 2006). The proposed enriched extension strain criterion can motivate and guide the development of new extension strain criteria, which remove some shortcomings of the MC criterion. It is particularly desirable to include the influence of the intermediate stress (Comanici and Barsanescu 2018). Existing stress failure criteria can be used as benchmark for the further improvement of extension strain criteria.

\section{Discussion}

\subsection{Mohr-Coulomb Strength Data}

An enriched extension strain criterion has been proposed, which is mathematically equivalent to the MC criterion. The latter, however, is typically presented with different data as critical relation between shear stress $\tau$ and normal stress $\sigma$ on the failure plane,

$|\tau|=S_{0}+\sigma \tan \phi$,

where $S_{0}$ is the inherent shear strength also known as cohesion and $\phi, 0^{\circ} \leq \phi<90^{\circ}$, is the angle of internal friction. However, the MC constants $S_{0}$ and $\phi$ are difficult to determine and can be estimated indirectly by linear regression based on the Hoek-Brown failure criterion (Hoek and Brown 1997; Shen et al. 2012) or are obtained from a simulation model. Disregarding this difficulty, $S_{0}$ and $\phi$ are used to drive the theoretical strength data,

$T_{0}=S_{0} \frac{2 \cos \phi}{1+\sin \phi}, \quad C_{0}=S_{0} \frac{2 \cos \phi}{1-\sin \phi}$,

where $T_{0}$ and $C_{0}$ are, respectively, the theoretical uniaxial tensile and compressive strength (Labuz and Zang 2012). The theoretical data is typically not observed in tests of geomaterials, Table 3. The observed uniaxial tensile stress $T$ is often much lower than $T_{0}$, i.e., $T_{0} \gg T$. In uniaxial compression, a distinction between observed and theoretical strength is not needed, because $C_{0} \approx C$ according to Labuz and Zang (2012).

This observation also has some implications for the enriched extension strain criterion. It is suggested in Labuz and Zang (2012) to use the preceding Eqs. (8), (10)-(12) with the theoretical values

$m_{0}=\frac{C_{0}}{T_{0}}=\frac{1+\sin \phi}{1-\sin \phi} \geq 1, \quad K_{0}=\frac{m_{0}-1}{m_{0}+1}=\frac{C_{0}-T_{0}}{C_{0}+T_{0}}=\sin \phi$, $C_{0}=2 S_{0} \sqrt{m_{0}}$

in connection with a Rankine tension cut of the MC failure limit at $T$. The strength ratio $m_{0}$ is independent of $S_{0}$.

Alternatively, the MC data $\phi_{\#}$ and $S_{\#}$ could be derived from measured $T$ and $C$ using,

$\phi_{\#}=\arcsin \left(\frac{m-1}{m+1}\right), \quad S_{\#}=\frac{1}{2} \sqrt{C T}$,

so that the $\mathrm{MC}$ theoretical and the observed uniaxial strength are the same, i.e., $C_{0}=C$ and $T_{0}=T$. But now, the observed MC parameters $\phi$ and $S_{0}$ are different from the calculated parameters $\phi_{\#}$ and $S_{\#}$ in Tables 3 and 4 . A similar approach is used in Sivakugan et al. (2014) with Eq. (14) but with the Brazilian indirect tensile strength test, which is not uniaxial, with the relation $T=S \cos \phi /(2-\sin \phi)$. It is found that some shear angles are calculated unrealistically small or even negative.

With respect to the enriched extension strain criterion, which is based on the Poisson effect, exactly Eq. (16) has been derived with $m_{0}$ replaced by the Poisson's ratio $v$ in (Turk and Dearman 1986). Using the MC criterion, five relations between $v$ and $m_{0}$ have been derived for intact solids in Zhang et al. (2011) from which $v=1 /\left(2 \sqrt{m_{0}}\right)$ among other relations is proposed (Lógó and Vásárhelyi 2019). For the enriched extension, strain criterion $v=1 /\left(2 m_{0}\right)$ is derived. The Poisson's ratio $v$ can be compared with $m_{0}$ or $m$, although the observed $v$ is not constant as assumed in linear elasticity, if damage occurs. 
Table 4 Measured values of mean values $\phi, S_{0}, C, T, v, E$, and density $\rho$ from literature

\begin{tabular}{llllll}
\hline Lithology & $\begin{array}{l}\text { Chalk marl (Barton } \\
\text { and Shen 2018) }\end{array}$ & $\begin{array}{l}\text { Phyllite, intact rock } \\
\text { (Panthee et al. 2016) }\end{array}$ & $\begin{array}{l}\text { Slate, intact rock (Pan- } \\
\text { thee et al. 2016) }\end{array}$ & $\begin{array}{l}\text { Lac du Bonnet granite, intact } \\
\text { (Hajiabdolmajid et al. 2002) }\end{array}$ & $\begin{array}{l}\text { Concrete grade C30 } \\
\text { (Lelović et al. 2019) }\end{array}$ \\
\hline$\phi\left(^{\circ}\right)$ & 30 & 26 & 28 & 48 & 31 \\
$\left.\phi_{\#}{ }^{\circ}\right)$ & 71 & 51 & 61 & 66 & 35 \\
$S_{0}(\mathrm{MPa})$ & 1.73 & 27 & 31 & 25 & 1.8 \\
$S_{\#}(\mathrm{MPa})$ & 0.51 & 15 & 12 & 24 & 9.5 \\
$C(\mathrm{MPa})$ & 6 & 82 & 93 & 224 & 36.31 \\
$C_{0}(\mathrm{MPa})$ & 5.99 & 86.4 & 103 & 130 & 6.36 \\
$T(\mathrm{MPa})$ & 0.173 & 10.4 & 6.4 & 10 & 3.02 \\
$T_{0}(\mathrm{MPa})$ & 2 & 33.7 & 37.3 & 19.1 & 2.04 \\
$m$ & 34.7 & 7.89 & 14.5 & 22.4 & 12.0 \\
$m_{0}$ & 2 & 2.56 & 2.77 & 6.81 & 3.12 \\
$v$ & 0.25 & 0.26 & 0.23 & 0.2 & 0.15 \\
$1 /(2 v)$ & 2 & 1.9 & 2.2 & 2.5 & 3.3 \\
$E(\mathrm{GPa})$ & 0.6 & 9 & 1.5 & 60 & 32 \\
$\varepsilon_{T}(\%)$ & 0.029 & 0.116 & 0.427 & 0.017 & 0.0094 \\
$\varepsilon_{T 0}(\%)$ & 0.33 & 0.374 & 2.49 & 0.032 & 0.0064 \\
$\rho\left(\mathrm{kg} / \mathrm{m}^{3}\right)$ & 2000 & 2740 & 2740 & - & - \\
\hline
\end{tabular}

Calculated values $C_{0}, T_{0}, \phi_{\#}, S_{\#}, m, m_{0}, \varepsilon_{T}$, and $\varepsilon_{T 0}$

In Table 4 , it is found that $m_{0}=1 /(2 v)$ for chalk mar; otherwise, $m_{0} \approx 1 /(2 v)$ except of Table 1 and generally $m \gg 1 /(2 v)$. The theoretical critical extension (tensile) strain in uniaxial stress and the elastically calculated value are,

$\varepsilon_{T 0}=\frac{T_{0}}{E}=\frac{C_{0}}{E m_{0}} \quad$ and $\quad \varepsilon_{T}=\frac{T}{E}=\frac{C}{E m}$,

respectively. It is found that the critical strain is rather low even if derived from theoretical strength data, because it is computed linear elastically with $E$ (except of $\varepsilon_{T 0}$ in Table 4 for slate, intact rock). The evolution of crack damage leads to a loss of stiffness before global fracture, so that measured strains at failure may be larger than $\varepsilon_{T}$ and $\varepsilon_{T 0}$. Therefore, different choices of material data for critical strain vs failure strain are discussed in Li et al. (2000) and Daraei and Zare (2018).

From the MC criterion, the enriched extension strain criterion inherits the problem of the discrepancy between strength observed in different tests of geomaterials and theoretical tensile strength data. The data in Tables 3 and 4 and the analysis of data in, e.g., Panthee et al. (2016) and Lelović et al. (2019) show that the theoretical values $T_{0} \approx 2 v C_{0}\left(m_{0} \approx 1 /(2 v)\right)$ are closer to the prediction of the extension strain criterion than the observed values $T \ll 2 v C$. Following Labuz and Zang (2012), the enriched extension strain criterion should be used with the theoretical strength concept of the MC criterion for best coincidence with the MC criterion. However, the favorable Table 3 only represents experts' estimations of data for classes of rock mass quality. In actually tested rocks, it is found that the theoretical data $T_{0}$ and, therefore, $\varepsilon_{T 0}$ are not measured in experiments. Table 4 shows that the prediction $C_{0} \approx C$ in (Labuz and Zang 2012) is only found in one case (chalk marl). The case that $C_{0} \ll C$ for limestone is even related to the strange finding $T_{0}<T$.

Some reasons of the discrepancy that have been put forward are, among others, the use of the cost-effective indirect tensile test (Brazilian test) and the over estimation of $C, T$ if $C_{0}, T_{0}$ are obtained from the linear MC approximation of the nonlinear shear failure envelope $\tau=f(\sigma)$ (Muralha et al. 2014). As the derivation of the enriched strain criterion has not made any recourse to the MC parameters $\phi$ and $S_{0}$, it is recommended to avoid the problems of the theoretical MC strength data $m_{0}$ and to use only the measured strength data. Also, in the enriched extension strain version, the theoretical strength data $v$ needs to be replaced for better results. However, in context of progression of rock damage, it becomes more plausible that the discrepancy originates from the difference between direct extension facture by tensile loading and indirect extension fracture due to the interplay of compressive loading and the Poisson effect.

The differences between measured strength and the MC theoretical strength lead to some inconsistency as can be seen in Fig. 5 for phyllite, intact rock, with data from Table 4 


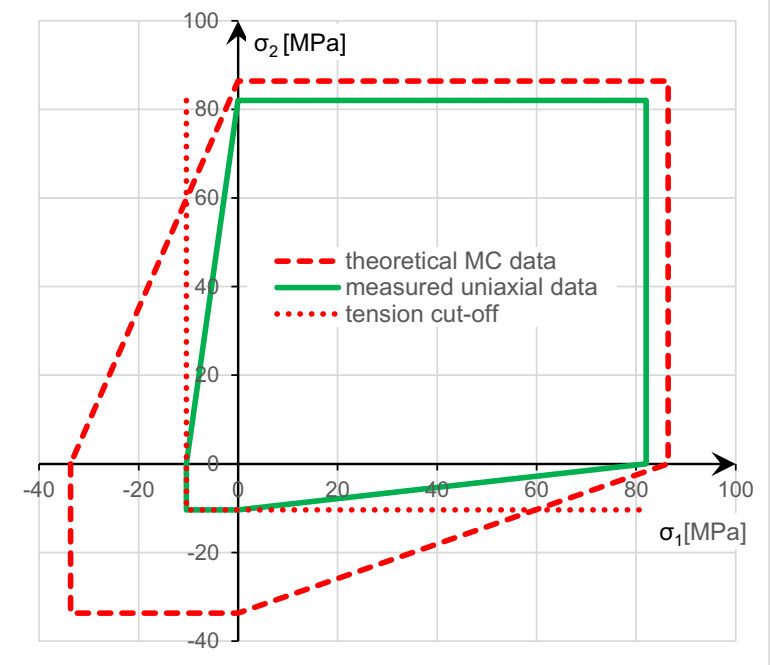

(a) Principal stress space (strength diagram)

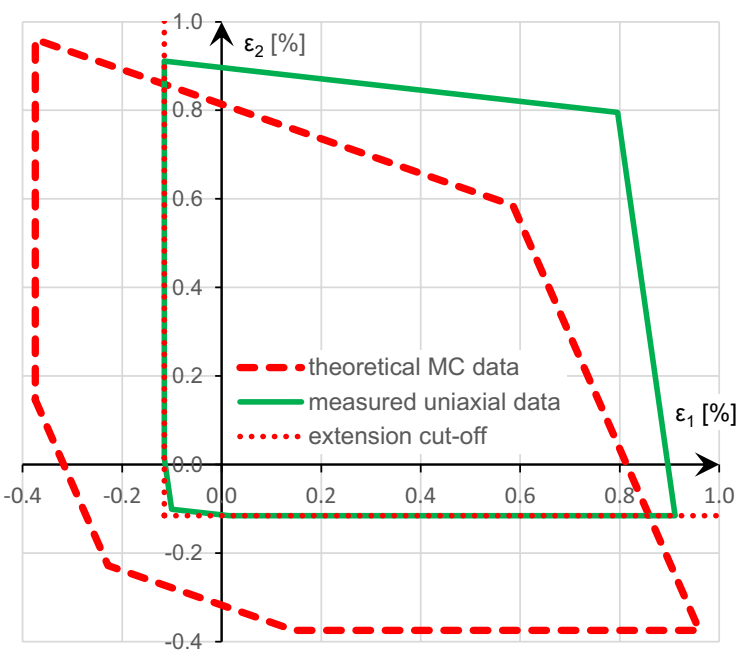

(b) Principal strain space (forming limit diagram)

Fig. 5 Comparison of the enriched extension strain failure criterion for phyllite, intact rock using data in Table 4: theoretical MC data $C_{0}=86.4 \mathrm{MPa}, T_{0}=33.7 \mathrm{MPa}$ and measured data $C=82 \mathrm{MPa}$, $T=10.4 \mathrm{MPa}$ with $E=9 \mathrm{GPa}$

and $C_{0} \approx C$. The large difference between $T_{0}=33.7 \mathrm{MPa}$ and $T=10.4 \mathrm{MPa}$ can be partly compensated by a Rankine tension cut-off in stress space. In strain space, a de Saint Venant extension cut-off would be the natural choice; Fig. 2b shows the changes if a Rankine cut-off would be used in strain space. However, the difference between $m=7.89$ and $m_{0}=2.56$ changes the failure envelope in strain space in the 1st quadrant of biaxial compression, so that the strain failure envelope would be different in this quadrant even if $C_{0}=C$. Elastic data $E$ are required for strain space presentation.

\subsection{Strain-Based Methods for the Determination of Crack Thresholds}

\subsubsection{Progressive Brittle Failure in Uniaxial Compression Tests}

It is questionable whether Hooke's law can be used to derive the extension strains, because the evolution of crack damage generally renders $E$ and as well as the transverse strain in uniaxial compression tests and the volumetric strain curves nonlinear, so that the total Poisson's ratio $v_{a}$ is not constant. Moreover, the elastic constants $E$ and $v$ of some rocks can be different in compression and tension tests (Sundaram and Corrales 1980; Stimpson and Chen 1993).

The fracture process in heterogeneous brittle materials in compression tests comprises three stages (Dyskin 1998): (1) accumulation of wing cracks formed under compression at tips of pre-existing cracks, (2) stable growth of larger cracks (mesocracks) normal to the compression stress, and (3) development of unstable macrocracks which eventually lead to failure. Since the early work of (Brace et al. 1966; Bieniawski 1967), it is now fairly standard to discuss the strains in the uniaxial compression test in five stages of crack development with diagrams similar to Fig. 6 (Martin and Chandler 1994; Eberhardt et al. 1999; Damjanac and Fairhurst 2010; Perras and Diederichs 2014; Hoek and Martin 2014a; Barton and Shen 2017; Zhao et al. 2018; Heidarzadeh et al. 2021). Figure 6 shows the five stages which are separated by the crack closure stress $C_{\mathrm{CC}}$ and three characteristic stress thresholds: crack initiation $C_{\mathrm{CI}}$, crack damage $C_{\mathrm{CD}}$ and peak $C_{P}$, which, however, are not sharply visible on the standard uniaxial stress strain curve, because $E$ is fairly constant.

Various methods that have been proposed to find the stress thresholds are tabulated in Xue et al. (2014) and may be understood by looking at the colored circles in Fig. 6. Crack growth can be "heard" as acoustic emission (AE). The development of cracks can be observed from the strains, because most rocks become dilatant, that is, their volume increases relative to elastic volume changes under loading. Serpentinites are a noted exception (Escartín et al. 1997).

Sharp crack tips lead to $1 / \sqrt{r}$ stress singularities. Let a crack oriented in the direction of the principal stress direction be opening in I mode and let the plane strain stress intensity factor $K_{I}(a)$ be a function of crack size $a$, so that the stresses and strains have the same singularity

$\sigma_{1}=\sigma_{2}=\frac{K_{I}(a)}{\sqrt{2 \pi r}}, \quad \varepsilon_{1}=\varepsilon_{2}=\frac{K_{I}(a)}{\sqrt{2 \pi r}}\left(\frac{1-v}{E}\right)=\frac{K_{I \varepsilon}(a)}{\sqrt{2 \pi r}}$ 


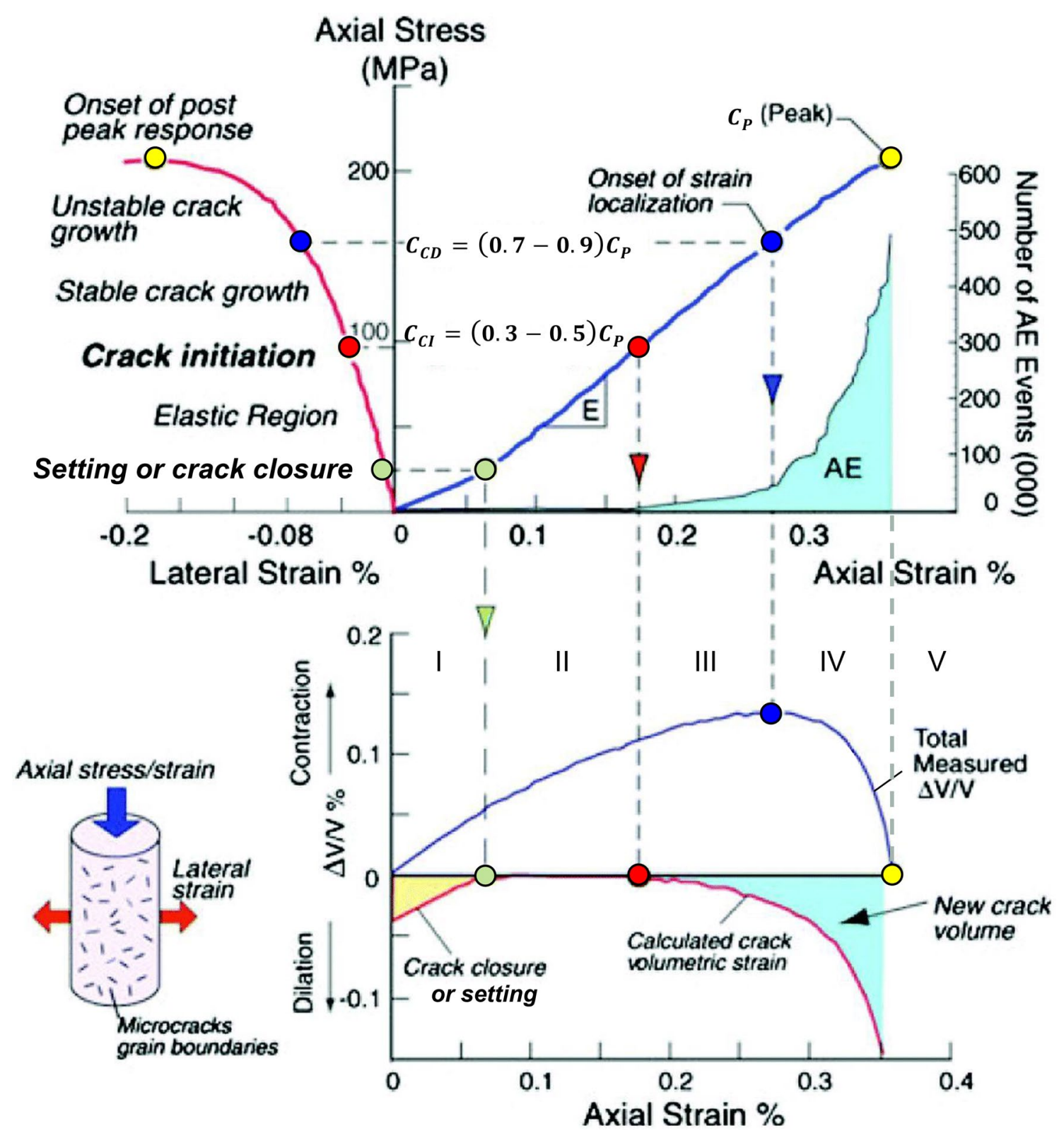

Fig. 6 Stages in the progressive brittle failure of intact Lac du Bonnet granite (from Zhao et al. 2018, modified, colors in online publication)

in (isotropic) linear-elastic fracture mechanics (LEFM) and the strain intensity factor $K_{I \varepsilon}=K_{I}((1-v) / E)$ is proportional to the stress intensity factor. Therefore, it seems appropriate to discuss cracks with regard to the stress thresholds on the basis of strain criteria and dilatancy.

With regard to the extension strain criteria, it is important to see that the total strain $\varepsilon_{i j}$ is brought about by elastic strain $\varepsilon_{i j}^{e}$ following isotropic Hooke's law and inelastic damage strain $\varepsilon_{i j}^{d}$ caused by crack like voids (Lubarda et al. 1994). The (small deformations) additive split $\varepsilon_{i j}^{d}=\varepsilon_{i j}-\varepsilon_{i j}^{e}$ is used to calculate the small deformations volumetric strain as the trace $\varepsilon_{v o l}=\Delta V / V=\varepsilon_{i i}=\varepsilon_{1}+\varepsilon_{2}+\varepsilon_{3}=\left(1-2 v_{a}\right) \varepsilon_{1}$ and the inelastic crack volumetric strain or dilatancy as $\varepsilon_{c r v}=\varepsilon_{i i}^{d}$ (Martin and Chandler 1994). This extension dilatancy is different from shear dilatancy in sand (Reynolds 1885). The elastic Poisson's ratio $v=\varepsilon_{\text {lat }}^{e} / \varepsilon_{1}^{e}$ and $E$ are constant, so that Hooke's law applies, whereas the total Poisson's ratio $v_{a}=\varepsilon_{\text {lat }} / \varepsilon_{1}$ is not constant, because it is a function of the nondecreasing (crack) damage parameter, which is an internal variable that measures the accumulation of damage. Acoustic emission (AE) can be used to measure the damage parameter (Zhang et al. 2019).

With these preparations, the following short presentation can be based on the diagrams in Fig. 6. 


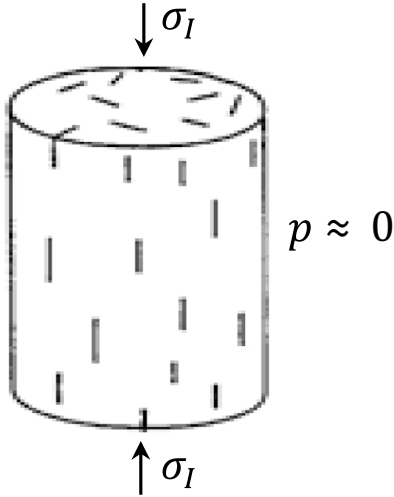

(a)

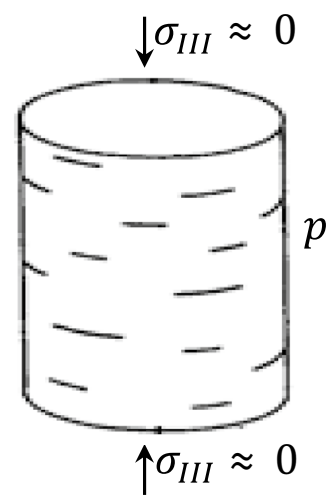

(b)
Fig. 7 Two transverse isotropic cracking arrangements normal to extension strains: a cylindrical produced by uniaxial compression $\sigma_{\mathrm{I}}>0$ and low or no confinement $\sigma_{\mathrm{II}}=\sigma_{\mathrm{III}}=p \approx 0$; b planar produced by equibiaxial compression $\sigma_{\mathrm{I}}=\sigma_{\mathrm{II}}=p>0, \sigma_{\mathrm{III}} \approx 0$ (this has been proposed in Chaboche 1993 for uniaxial tension)

Stage I Closure of microcracks (from origin up to the crack closure stress $C_{\mathrm{CC}}$ ).

This stage is observed during the initial stage of loading if the crack density is not too low (intact rock). Preexisting cracks oriented at some angles to the applied compressive stress close in loading direction. Eberhardt et al. $(1998,1999)$ pointed out that this region involves movement of aligned crack walls toward one another, parallel to the direction of the maximum compressive stress vector (stress times area). Later, Korinets and Alehossein (2002) have shown in that the effect is dominated by the setting of (asperities and voids), which occurs localized at the contact to the load platens, so that the "crack closure stress" may be a misnomer and does not present a threshold value. This initial setting causes a (concave) non-linearity of the axial stress-strain curve, exhibiting an increase in axial stiffness.

Stage II Linear elastic deformation (from $C_{\mathrm{CC}}$ to the crack initiation stress $C_{\mathrm{CI}}$ at the initiation of stable crack growth).

At this stage, the rock often behaves as a linear-elastic, homogeneous material. Elastic constants of the rock can be calculated from this linear portion of the stress-strain curve as tangent values $E_{t 50}, v_{t 50}$ or secant values $E_{s 50}, v_{s 50}$ from the range of $-0.01 \%$ radial (lateral) strain to $50 \%$ of peak stress.

Stage III Stable crack propagation or onset of dilatancy (from $C_{\mathrm{CI}}$ to the crack damage stress $C_{\mathrm{CD}}$ at the initiation of unstable crack growth).

The stress $C_{\mathrm{CI}}$ is the onset of micro-cracking and the threshold of relative dilatancy. At $C_{\mathrm{CI}}$, the crack volume increases mainly by the generation of new cracks, the propagation of old cracks, and the sliding between crack surfaces. Crack initiation (CI) represents the first occurrence of new distributed particle size cracks and can be associated with the occurrence of non-linearity in the stress versus lateral (extension) strain curve or identified with the maximum in the crack volume-strain curve. The long-term strength of rock is $C_{\mathrm{CI}}$ or close to $C_{\mathrm{CI}}$. Stable crack growth can be terminated by controlling the applied load. Dilation is caused only by lateral strains and thus reflects the development of cracks parallel to the direction of the applied load. This point is difficult to see from the stress-strain curve, especially if the specimen has a high microcrack density. CI is best determined with a plot of volumetric crack strain against axial strain (Martin and Chandler, 1994). Eberhardt et al. (1998) note that CI has been defined as the point at which the lateral strain curve deviates from linearity. Alternative methods including AE are compared in Gao et al. (2018). Stable (slow) crack growth leads to an orientation of cracks orthogonal to the extension strain (lateral strain), resulting in the cylindrical transverse isotropic cracking arrangement described by Chaboche (1993), illustrated in Fig. 7a.

Stage IV Unstable fracture propagation (from $C_{\mathrm{CD}}$ to the ultimate (peak) stress $C_{P}$ at the initiation of unstable crack growth).

The stress $C_{\mathrm{CD}}$ is the threshold of absolute dilatancy. Coalescence of microcracks increases crack sizes $a$ and the number of unstable cracks. Strain localizes at crack tips and instability occurs at a critical value of $K_{I}(a)$. The unstable crack growth is associated with the point of reversal in the volumetric strain curve, which is also known as the point of critical energy release or crack damage (Martin and Chandler, 1994). The volume dilates up to $C_{\mathrm{CD}}$ at the maximum of the volumetric strain and contracts above $C_{\mathrm{CD}}$. The crack damage stress $C_{\mathrm{CD}}$ is also denoted the short-term strength of rock, because even if the load is reduced, the internal cracks cannot hold stable for a significant amount of time and deformations continue up to rupture over time. Unstable (rapid) crack propagation can be related to the occurrence of (convex) non-linearity in the curve of stress vs. strain in loading direction or to the maximum in the volume strain $\left(\varepsilon_{\mathrm{vol}}=\Delta V / V\right)$ curve. The peak point is the ultimate compression stress UCS or $C_{p}$ for short notation in formulae.

Stage $V$ Failure and post-peak behavior.

Unstable growth of macrocracks continues to the point where the numerous microcracks have coalesced and the rock can no longer support an increase in load (Eberhardt et al. 1998) and fails by axial splitting as in Fig. 1a. The peak strength of the material, $C_{P}$, marks the beginning of postpeak behavior and is used to establish the failure strength envelope (Martin and Chandler 1994).

Only reversible macroscopic strains occur below $C_{\mathrm{CI}}$, so that no failure occurs (except of the hypothetical case of high cycle fatigue). Between $C_{\mathrm{CI}}$ and $C_{P}$ elastic and irreversible strains occur, which may lead to failure, so that $C_{\mathrm{CI}}$ and $C_{P}$ can be considered as lower and upper bound failure 
thresholds, respectively. It could be detailed that failure can potentially occur between $C_{\mathrm{CI}}$ and $C_{\mathrm{CD}}$ and is inevitable between $C_{\mathrm{CD}}$ and $C_{P}$. Some authors consider the lower bound $C_{\mathrm{CI}}$ of in situ rock strength as the more important threshold in rock engineering (Wei et al. 2018). Observations from underground mining in massive brittle rocks suggest that failure initiates when the maximum tangential boundary stress reaches approximately $40 \%$ of UCS $\left(0.4 C_{P}\right)$, which is close to $C_{\mathrm{CI}}$. Also, the long-term strength threshold in crystalline rock is found around $0.4 C_{P}$ (Damjanac and Fairhurst 2010). $C_{\mathrm{CI}}$ and $C_{\mathrm{CD}}$ can be useful for preliminary engineering design, especially when the definition of a warning indicator for rock mass damage and breakouts is needed (Pepe et al. 2018).

Similar to rock mechanics, the stress thresholds $C_{\mathrm{CI}}$ and $C_{\mathrm{CD}}$ are considered suitable for use as bases for lower and upper bound failure criteria for concrete structures in conformity with the limit state requirements of serviceability and ultimate strength, respectively (Newman and Kotsovos 1977; Kotsovos 1979). This is supported by experiments, which indicate a close correlation between $C_{\mathrm{CI}}$ and the (low cycle) fatigue strength of concrete and between $C_{\mathrm{CD}}$ and the long-term strength of concrete below which concrete does not collapse under sustained load (Kotsovos 1979).

In contrast to the peak strength (Hudson et al. 1972, 2003), it has been suggested that the above dilatancy thresholds $C_{\mathrm{CI}}$ and $C_{\mathrm{CD}}$ are true characteristic material parameters of rocks, which do not depend on the loading conditions in material tests (Martin and Chandler 1994). However, in damage-controlled tests, they all drop with the accumulation of damage, most strongly for $C_{\mathrm{CD}}$ and $C_{P}$. For larger damage, $C_{\mathrm{CD}}$ assumes the low values of $C_{\mathrm{CI}}$ in the limit and both stabilize at some asymptotic value (Lau and Chandler 2004; Paraskevopoulou et al. 2017). Although the different suggested methods determine the thresholds with different certainty, the mean values of the stress thresholds can be approximated by the same percentage of $C_{P}$ for most rocks in monotonous loading (Taheri et al. 2020): $C_{\mathrm{CC}}=0.21 C_{P}$, $C_{\mathrm{CI}}=0.33 C_{P}$, and $C_{\mathrm{CD}}=0.8 C_{P}$.

\subsubsection{Progressive Brittle Failure in Multiaxial Loading}

The plasticity criteria proposed in the literature are criticality criteria related to $C_{P}$, whereas the inelastic processes below $C_{P}$ are more subtle leading to dilatancy criteria related to $C_{\mathrm{CI}}$ and $C_{\mathrm{CD}}$, which are less sharply detected. Although a literature dataset on intact rocks from more than 480 uniaxial compression tests could be analyzed in Pepe et al. (2018), there is only restricted information on multiaxial loading. In biaxial compression, stable (slow) crack growth wing cracks form at the ends of arbitrarily oriented parent cracks leading to an orientation of enlarged cracks orthogonal to the extension strain, but unlike uniaxial compression, this

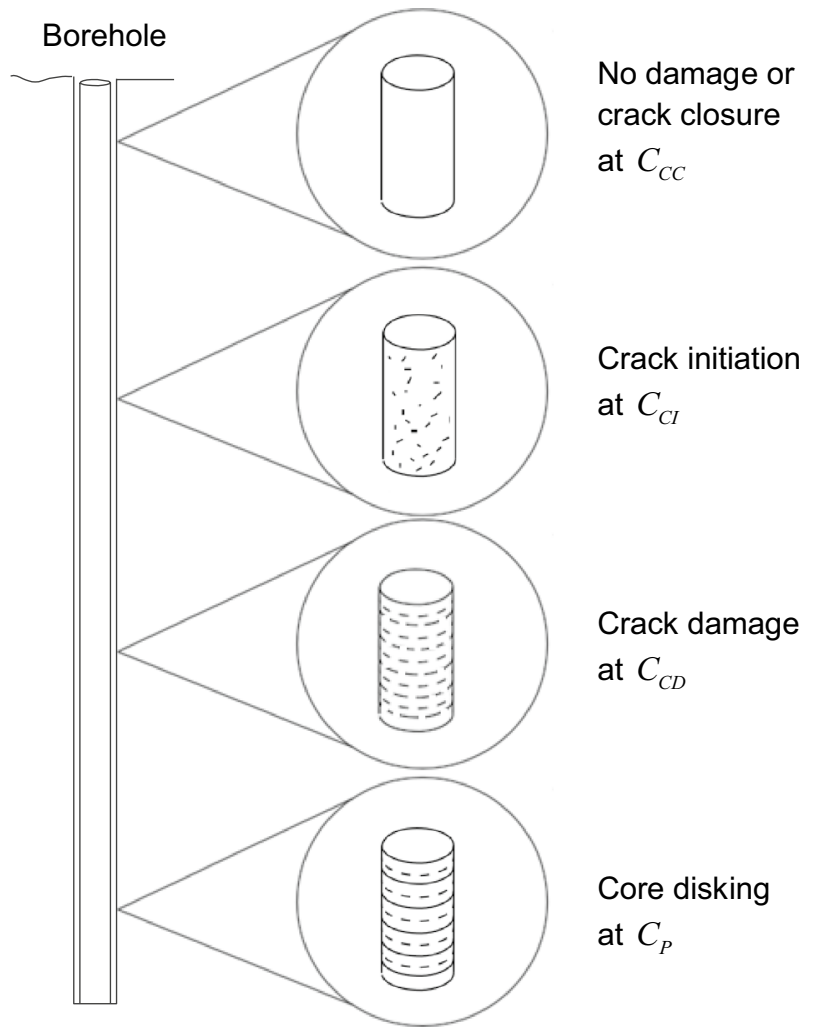

Fig. 8 Coring-induced micro cracks in case of equibiaxial stress in a vertical borehole. Areal fracture intensity (crack density and size) increase with depth (after Martin and Stimpson 1994 but crack damage with crack orientation adapted to extension cracking in Fig. 7b)

leads to planar isotropic crack arrangement, as depicted in Fig. 7b. This process also occurs in less granular materials like ice and is geometrically somewhat more complicated in 3D, (Kolari 2019). In a vertical borehole, the equibiaxial stress, which increases with depth, drives the core through the same sequence of $C_{\mathrm{CC}}$ and the stress thresholds $C_{\mathrm{CI}}, C_{\mathrm{CD}}$, and $C_{P}$ as in uniaxial compression. As shown in Fig. 8, at $C_{\mathrm{CD}}$ microcracks extend in the orientation shown in Fig. 7b and finally lead to disking at $C_{P}$ as in Fig. 1 b.

In multidimensional loading $C_{\mathrm{CI}}, C_{\mathrm{CD}}$, and $C_{P}$ are represented by threshold or failure surfaces, which can either be based on different failure criteria or all on the same failure criterion. A modification to the Griffith's theory is proposed for $C_{\mathrm{CI}}$ in Wei et al. (2018). Lubarda et al. (1994) use a generalized MC surface as damage surface with $C_{\mathrm{CD}}$ strength data. A parabolic Drucker-Prager yield surface in compression and a linear failure surface in tension are used in Nguyen and Houlsby (2008). For concrete, an extended Ottosen failure surface is compared to other models for the yield envelope and for the peak envelope in Contrafatto and Cuomo (2007). The Hoek-Brown criterion is used for the thresholds $C_{\mathrm{CI}}, C_{\mathrm{CD}}$, and $C_{P}$ of rock in (Hoek and Martin 2014). Stacey (1981) has proposed the simple extension 
strain criterion with the critical strain at the crack initiation threshold $C_{\mathrm{CI}}$. This has the advantage that Hooke's law can be assumed to hold but the disadvantage that the criterion predicts very large volumes of failing rock, because the low values of the $C_{\mathrm{CI}}$ threshold coincide with the prediction of only $50 \%$ of the MC equivalent stress in equibiaxial compression. Burzyński (1929) and Beierlein (1985) have formulated the extension strain criterion independently for $C_{P}$, which is not realistic, because the experimental failure stress is found inside the MC surface for approximately equibiaxial compression. Buyukozturk (1977) proposes a generalized MC surface for $C_{\mathrm{CI}}$ and $C_{P}$.

The Griffith criterion assumes that tensile failure in brittle materials initiates at crack tips which extend if the plane strain fracture toughness $K_{\text {IC }}$ is exceeded under predominantly linear-elastic conditions by the stress intensity $K_{I}$ for crack opening mode I (Griffith 1924). This is based on fracture mechanics and assumes tensile fracturing with uniaxial tensile strength $T$ as material parameter,

$\begin{array}{ll}8 T\left(\sigma_{1}+\sigma_{3}\right)+\left(\sigma_{1}-\sigma_{3}\right)^{2}=0 & \text { if } \sigma_{1}+3 \sigma_{3} \geq 0, \\ T-\sigma_{3}=0 & \text { if } \sigma_{1}+3 \sigma_{3}<0 .\end{array}$

The Griffith criterion can be transformed into the Mohr shear-normal stress space $4 T(T-\sigma)-\tau^{2}=0$. This gives a parabolic envelope, which can be used as continuation of the linear Mohr-Coulomb envelope Eq. (13) in tension. The values (but not the slopes) of the two curves match at $\sigma=0$ if $S_{0}=2 T$ is chosen, which fits well experimentally derived curves for shear failure.

Murrell's triaxial extension of the Griffith criterion (Murrell 1963),

$\left(\sigma_{1}-\sigma_{2}\right)^{2}+\left(\sigma_{1}-\sigma_{3}\right)^{2}+\left(\sigma_{2}-\sigma_{3}\right)^{2}-24 T\left(\sigma_{1}+\sigma_{2}+\sigma_{3}\right)=0$,

predicts realistic larger compressive strength $C$, because for $\sigma_{1}=C$, uniaxially $C=8 T$ and $C=12 T$ follow from (19) and (20), respectively. Different from the MC criterion, Murrel's criterion includes the dependence on the intermediate principal stress $\sigma_{2}$, but it severely overestimates strength, whereas the MC criterion is only slightly underestimating (Zheng and Deng 2015) and is preferred in compression. However, $T_{\mathrm{IC}}=C_{\mathrm{IC}} / 8$ or $T_{\mathrm{IC}}=C_{\mathrm{IC}} / 12$ can be used to apply the Griffith or the Murrell-Griffith criterion to estimate crack initiation in tension, which is difficult to measure in direct tension tests, Table 5. The table also uses the Brazilian tensile strength (BTS) estimation as alternative. In tensile tests, the failure process of rock also includes initiation, growth, and propagation of micro-fractures. However, this all happens when the axial stress is close to the tensile peak strength $T_{P}$. In uniaxial tension tests of norite, it is found that the crack initiation threshold is $T_{\mathrm{CI}}=0.95 T_{P}$ and the propagation threshold is $T_{\mathrm{CD}}=0.97 T_{P}$, respectively (Bieniawski
1967). Even closer to $T_{P}$, the AE initiation stress level of medium grained granite was found to be $T_{\mathrm{CI}}=0.98 T_{P}$ in Tham et al. (2005), so that $T_{\mathrm{CI}} \approx T_{\mathrm{CD}} \approx T_{P}$, which is also found in other rock in Perras and Diederichs (2014), can be simplified to,

$T_{\mathrm{CI}}=T_{\mathrm{CD}}=T_{P}$,

$m_{\mathrm{CI}}=\frac{C_{\mathrm{CI}}}{T_{\mathrm{CI}}}, \quad m_{\mathrm{CD}}=\frac{C_{\mathrm{CD}}}{T_{\mathrm{CI}}}, \quad m_{P}=\frac{C_{P}}{T_{\mathrm{CI}}}$.

This neglects the damage in tension and all damage evolves under compression, which results in a compression hardening behavior of damage evolution similar to Mazars (1986) and Mazars et al. (2015) shown in Fig. 9. In Mazars' model, however, only the initial damage surface is defined, while the damage evolution law finds the subsequent surfaces.

Compressive and tension failure mechanisms are reproduced according to the same extension fracture mode I driven by the principal extension strains. However, it is an apparent paradox that two theories of fracture are needed depending on whether the applied load is tensile or compressive. An essential difference is that whereas in tension the crack extension force increases with crack growth, in compression it decreases after a maximum value of the crack extension force is reached (Cotterell 1972). The number of cracks created indirectly by the Poisson effect in compression is much larger than the number of cracks created directly in tension (Karavelić et al. 2019). Therefore, different damage evolution should be modeled in tension and compression. In contrast to Eq. (21), the critical elastic strain thresholds can be assumed to be different and for a phenomenological extension strain criterion,

$\varepsilon_{T, \mathrm{CI}}=\frac{C_{\mathrm{CI}}}{m_{\mathrm{CI}} E}, \quad \varepsilon_{T, \mathrm{CD}}=\frac{C_{\mathrm{CD}}}{m_{\mathrm{CI}} E}, \quad \varepsilon_{T, P}=\frac{C_{P}}{m_{\mathrm{CI}} E}$,

so that

$m_{\mathrm{CI}}=\frac{C_{\mathrm{CI}}}{T_{\mathrm{CI}}}=\frac{C_{\mathrm{CD}}}{T_{\mathrm{CD}}}=\frac{C_{P}}{T_{P}}$,
$T_{\mathrm{CI}}=\frac{C_{\mathrm{CI}}}{m_{\mathrm{CI}}}, T_{\mathrm{CD}}=\frac{C_{\mathrm{CD}}}{m_{\mathrm{CI}}}, T_{P}=\frac{C_{P}}{m_{\mathrm{CI}}}$.

This leads to an isotropic hardening behavior of damage evolution shown for the enriched extension strain criterion in Fig. 10. The figure also shows a simple way to achieve different damage in tension and compression by tension and extension cut-off at $T_{\mathrm{CI}}$ and $\varepsilon_{T, \mathrm{Cl}}$, respectively.

The numerical analysis is based on the integration of damage models, which fully describe the nonlinear behavior of rock (Mazars et al. 2015; Jia et al. 2020). However, Mazars' material model is initially isotropic and the damage retains this isotropy with no dominating orientation 
Table 5 Mean, standard deviation, and minimum and maximum values for the granite, limestone, and mudstone properties

\begin{tabular}{|c|c|c|c|c|c|}
\hline Lithology & Property & $\begin{array}{l}\text { Mean }( \pm \text { standard } \\
\text { deviation) }(\mathrm{MPa})\end{array}$ & Min. (MPa) & Max. (MPa) & $\begin{array}{l}\text { No. of } \\
\text { tested } \\
\text { samples }\end{array}$ \\
\hline \multirow[t]{6}{*}{ Forsmark granite (Perras and Diederichs 2016) } & UCS & $246( \pm 23)$ & 187 & 289 & \multirow[t]{6}{*}{43} \\
\hline & $\mathrm{CI}$ & $125( \pm 16)$ & 96 & 172 & \\
\hline & $\mathrm{CD}$ & $206( \pm 17)$ & 167 & 238 & \\
\hline & $T=\mathrm{CI} / 8$ & $15.6( \pm 2)$ & 12 & 21.5 & \\
\hline & $T=\mathrm{CI} / 12$ & $10.4( \pm 1)$ & 8 & 14.3 & \\
\hline & $E$ & 69,900 & 30,500 & 82,900 & \\
\hline No dimension & $\nu$ & 0.28 & 0.21 & 0.38 & \\
\hline \multirow[t]{7}{*}{ Clay shale (Amann et al. 2011) } & UCS & $6.94( \pm 1.4)$ & 5.09 & 10 & \multirow[t]{7}{*}{19} \\
\hline & $\mathrm{CI}$ & $2.01( \pm 0.33)$ & 1.49 & 2.88 & \\
\hline & CI_EA & $2.26( \pm 1.48)$ & 0.94 & 5.84 & \\
\hline & $\mathrm{CD}$ & $4.84( \pm 1.55)$ & 2.40 & 7.66 & \\
\hline & $T=\mathrm{CI} / 8$ & $0.251( \pm 0.04)$ & 0.186 & 0.36 & \\
\hline & $T=\mathrm{CI} / 12$ & $0.168( \pm 0.03)$ & 0.124 & 0.24 & \\
\hline & $E$ & $1,689( \pm 381)$ & 1,013 & 2,394 & \\
\hline No dimension & $\nu$ & $0.16( \pm 0.04)$ & 0.11 & 0.21 & \\
\hline \multirow[t]{10}{*}{ Cobourg limestone $^{\mathrm{a}}$ (Perras and Diederichs 2016) } & UCS & $112( \pm 26)$ & 44 & 175 & \multirow[t]{7}{*}{60} \\
\hline & CI_TD & $45( \pm 11)$ & 24 & 75 & \\
\hline & CIU_AE & $41( \pm 12)$ & 21 & 65 & \\
\hline & CIL_AE & $38( \pm 11)$ & 21 & 60 & \\
\hline & $\mathrm{CD}$ & $97( \pm 27)$ & 45 & 162 & \\
\hline & $T=$ CI_TD $/ 8$ & $5.7( \pm 1.4)$ & 3 & 9.4 & \\
\hline & $T=$ CI_TD $/ 12$ & $3.7( \pm 1.5)$ & 2.4 & 5.9 & \\
\hline & $T=\mathrm{BTS}$ & $6.5( \pm 2.6)$ & 3.7 & 8.9 & \multirow[t]{3}{*}{9} \\
\hline & $T=0.7 \mathrm{BTS}$ & $4.5( \pm 1.8)$ & 2.5 & 6.1 & \\
\hline & $E$ & $38,000( \pm 8740)$ & 18,900 & 55,990 & \\
\hline No dimension & $\nu$ & $0.31( \pm 0.08)$ & 0.12 & 0.45 & \\
\hline \multirow[t]{7}{*}{ Quintner limestone (Perras et al. 2012) } & UCS & $96( \pm 32)$ & 53 & 143 & \multirow[t]{7}{*}{15} \\
\hline & $\mathrm{CI}$ & $46( \pm 9.6)$ & 34 & 67 & \\
\hline & $\mathrm{CD}$ & $78( \pm 23)$ & 43 & 105 & \\
\hline & $T=\mathrm{CI} / 8$ & $5.8( \pm 1.2)$ & 4.3 & 8.4 & \\
\hline & $T=\mathrm{CI} / 12$ & $3.8( \pm 0.8)$ & 2.8 & 5.6 & \\
\hline & $T=\mathrm{BTS}$ & $5.9( \pm 2.2)$ & 0.6 & 10.4 & \\
\hline & E_50 & $56,700( \pm 23,260)$ & 22,000 & 119,000 & \\
\hline \multirow[t]{6}{*}{ Cobourg limestone (Paraskevopoulou et al. 2017) } & UCS & $125( \pm 19)$ & 94 & 149 & \multirow[t]{6}{*}{9} \\
\hline & $\mathrm{CI}$ & $50( \pm 7)$ & 37 & 58 & \\
\hline & $\mathrm{CD}$ & $111( \pm 18)$ & 84 & 136 & \\
\hline & $T=\mathrm{CI} / 8$ & $6.25( \pm 0.88)$ & 4.6 & 7.3 & \\
\hline & $T=\mathrm{CI} / 12$ & $4.17( \pm 0.58)$ & 3.1 & 4.8 & \\
\hline & $E$ & $41,000( \pm 4000)$ & 36,000 & 47,000 & \\
\hline No dimension & $\nu$ & $0.15( \pm 0.04)$ & 0.11 & 0.24 & \\
\hline \multirow[t]{6}{*}{ Jurassic limestone (Paraskevopoulou et al. 2017) } & UCS & $103( \pm 23)$ & 66 & 126 & \multirow[t]{6}{*}{10} \\
\hline & $\mathrm{CI}$ & $39( \pm 9)$ & 22 & 50 & \\
\hline & $\mathrm{CD}$ & $91( \pm 21)$ & 53 & 125 & \\
\hline & $T=\mathrm{CI} / 8$ & $4.88( \pm 1.13)$ & 2.75 & 6.25 & \\
\hline & $T=\mathrm{CI} / 12$ & $3.25( \pm 0.75)$ & 1.83 & 1.17 & \\
\hline & $E$ & $93,000( \pm 25,000)$ & 71,000 & 125,000 & \\
\hline No dimension & $\nu$ & $0.23( \pm 0.55)$ & 0.12 & 0.29 & \\
\hline
\end{tabular}


Table 5 (continued)

\begin{tabular}{|c|c|c|c|c|c|}
\hline Lithology & Property & $\begin{array}{l}\text { Mean }( \pm \text { standard } \\
\text { deviation })(\mathrm{MPa})\end{array}$ & Min. (MPa) & Max. (MPa) & $\begin{array}{l}\text { No. of } \\
\text { tested } \\
\text { samples }\end{array}$ \\
\hline \multirow[t]{6}{*}{ Jurassic limestone (Paraskevopoulou et al. 2017) } & UCS & $48( \pm 15)$ & 19 & 70 & \multirow[t]{7}{*}{54} \\
\hline & CI & $19( \pm 6)$ & 8 & 29 & \\
\hline & $\mathrm{CD}$ & $32( \pm 12)$ & 15 & 50 & \\
\hline & $T=\mathrm{CI} / 8$ & $2.4( \pm 0.8)$ & 0.9 & 3.7 & \\
\hline & $T=\mathrm{CI} / 12$ & $1.6( \pm 0.5)$ & 0.6 & 2.5 & \\
\hline & $E$ & $14,500( \pm 6800)$ & 6,500 & 58,000 & \\
\hline No dimension & $\nu$ & $0.40( \pm 0.1)$ & 0.10 & 0.49 & \\
\hline
\end{tabular}

$\mathrm{CI}$ and $\mathrm{CD}$ are short for $\mathrm{C}_{\mathrm{CI}}$ and $\mathrm{C}_{\mathrm{CD}}$, respectively. CI_TD is for transducer measurements, and CI_AE based on AE measurements with CIU_ $\mathrm{AE}$ as upper and CIL_AE as lower bound

${ }^{a}$ For completion, some previously unpublished data have been added from the original sources as cited in Perras (2014): Technical Reports by Gorski B., Anderson T., Conlon T. in 2009 (TR-07-03, TR-08-11) and in 2010 (TR-8-24, TR-08-36) and by Gorski B., Rodgers D,. Conlon B. in 2011 (TR-09-07), DGR Site Characterization Document, Intera Engineering Project, Canada, https://www.nwmo.ca

of cracks. Therefore, the Poisson's ratio remains constant throughout the loading, so that shear dilatancy cannot be described. Isotropic hardening has been modeled for isotropic rock in Aubertin et al. (2000) for damage initiation $C_{\mathrm{CI}}$, short-term failure $C_{\mathrm{CD}}$, and peak $C_{P}$ with a failure surface, which is denoted $\mathrm{MSDP}_{\mathrm{u}}$ for von Mises-Schleicher \& Drucker-Prager unified and compared with biaxial tests of concrete. A realistic modeling of dilatation is achieved with non-associated plasticity, which implies the introduction of a dilatation angle, so that the normal to the MC failure surface is not obtained by the MC friction angle (Vermeer and de Borst 1984; Alejano and Alonso 2005).

The MC criterion has also been used in kinematic hardening models. In a simple form, the initial yield surface translates within a fixed bounding surface. This has been used for limit analysis in geomechanics (Krabbenhøft et al. 2007; Martin and Makrodimopoulos 2008). The observation $T_{\mathrm{CI}} \approx T_{\mathrm{CD}} \approx T_{P}$ can be satisfied by combining kinematic and isotropic hardening.

Intact rocks with random grain structure and crack orientation can be considered as isotropic. The formation and growth of wing cracks leads to crack orientation normal to the most negative (extension) strain and anisotropic strength. Anisotropic forms of the MC criterion have been suggested (Pietruszczak and Mroz 2001; Gesualdo and Monaco 2015; Pouragha et al. 2019). The representation as an enriched extension strain criterion must additionally account for elastic anisotropy. Modeling the anisotropy of strength and elasticity under the evolution of damage requires further theoretical and experimental research.

\subsection{Application of the Criteria to Excavation Problems}

The MC criterion has the widest application in rock mechanics and its prediction quality has been extensively evaluated in material tests with multiaxial loading. Therefore, the same quantitative validation can be considered as given for the enriched extension strain criterion. The main problem is that the effect of the intermediate stress is not represented in the $\mathrm{MC}$ criterion. This is therefore also missing in the enriched extension strain criterion. Having identified the problems with the failure envelope of the simple extension strain criterion, the consequences can now be discussed in application to two rock problems with care to the separation between the effects of criteria and strength data. The data in Table 6 show that only the MC theoretical data are known and used.

\subsection{Excavation Damage Zone in Circular Tunnels}

For application of rockburst prediction methods to tunnels under hydrostatic stress condition in massive rock mass, an extension of Aydan's method for tunnels in squeezing rocks to rock bursting can be applied (Aydan and Geniş 2010; Aydan et al. 2017). The well-known instability phenomenon in mining, the strain bursting (rock bursting), is generally associated with the violent extensional failure of brittle hard rock masses such as igneous rocks, gneiss, quartzite, and siliceous sandstone under high in situ compressive stresses. An empirical formula for the estimate of the maximum extent of brittle failure in the area of sub-surface excavations was fit in (Perras and Diederichs 2016) based on an empirical plot from Martin et al. (1999), $C_{\mathrm{CI}}$ and case studies in which the maximum damage depth was investigated through intense scaling. 


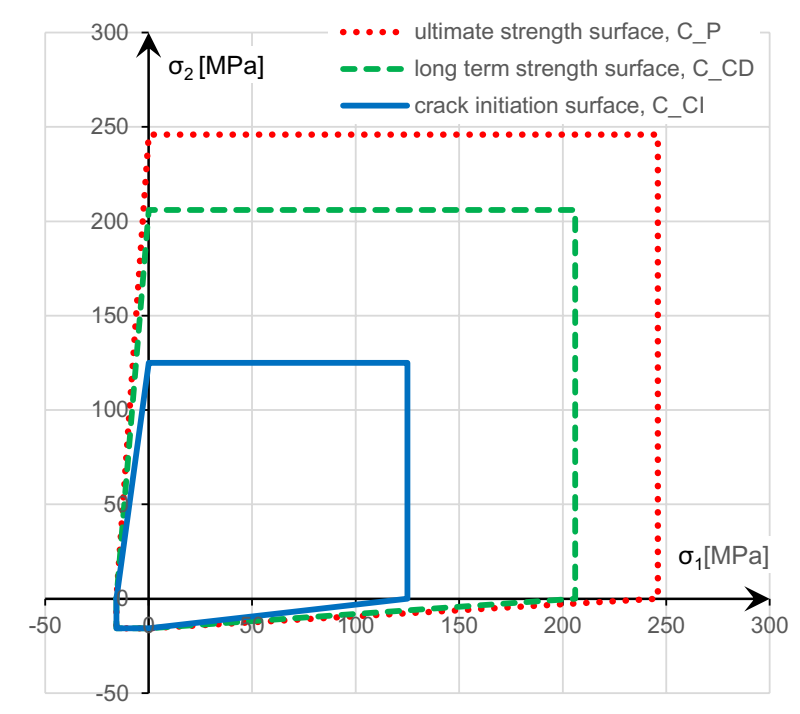

(a) Principal stress space (strength diagram)

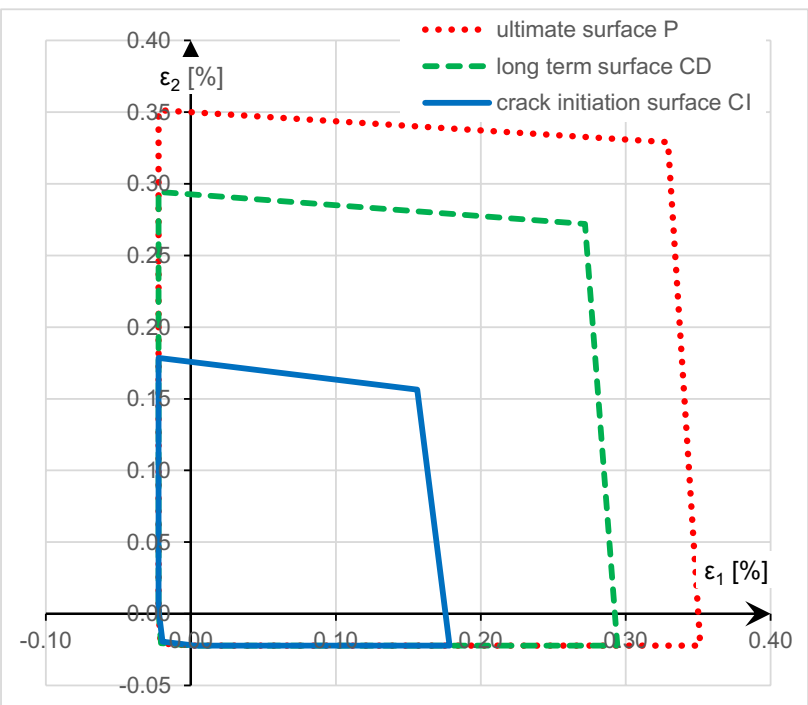

(b) Principal strain space (forming limit diagram)

Fig. 9 Compressive damage evolution in progressive failure of rock following Eq. (21) for Forsmark granite with data in Table 5 (colors in online publication)

A first simple estimation can be made on the basis of the Kirsch's classical far field solution of stress concentration for the tangential tensile stress around a circular hole (Kirsch 1898). For circular tunnels in depth $h$ of radius $R$ under a simplified overburden in form of hydrostatic initial pressure $p_{0}=\rho g h$ state and the internal support pressure $p_{i} \approx 0$ in the tunnel as shown in Fig. 11, the failed zone radius $R_{p}$ can be calculated more realistically using the two dimensionless variables,

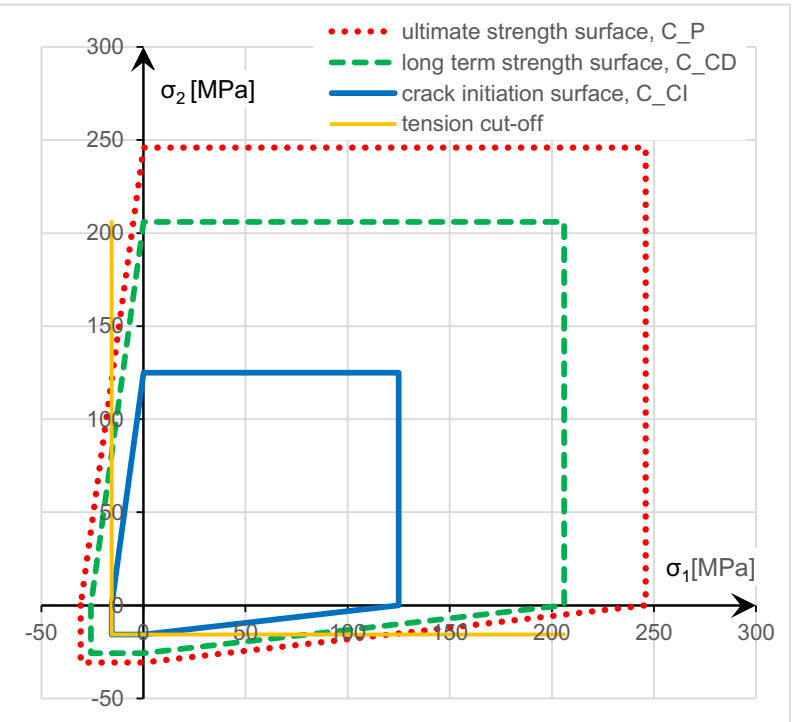

(a) Principal stress space (strength diagram)

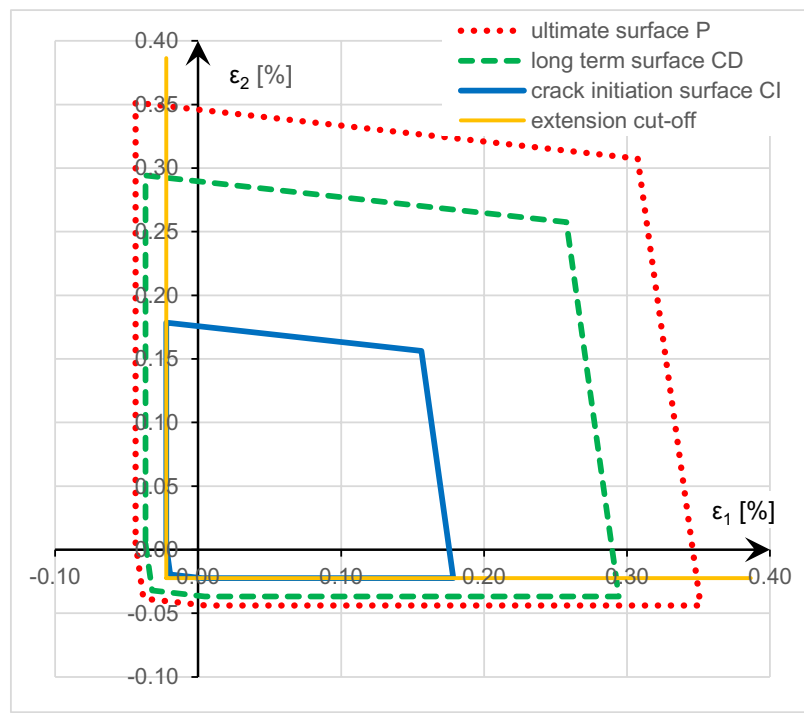

(b) Principal strain space (forming limit diagram)

Fig. 10 Isotropic model of damage evolution in progressive failure of rock following Eqs. (22), (23) for Forsmark granite with data in Table 5. Different damage in tension and compression is achieved with tension and extension cut-off at $T_{\mathrm{CI}}$ and $\varepsilon_{T, \mathrm{CI}}$, respectively (colors in online publication)

$b=\frac{p_{i}}{p_{0}} \approx 0, \quad a=\frac{C_{0}}{p_{0}}$.

Hoek (1999) inferred from the perfectly plastic (pp) critical pressure for the MC criterion, 
Table 6 Rock mass data of estimated data (bold) from given references and calculated values

\begin{tabular}{llll}
\hline & $\begin{array}{l}\text { Good quality (Aydan and } \\
\text { Geniş 2010) }\end{array}$ & $\begin{array}{l}\text { Eldorado reef, hanging wall (le } \\
\text { Roux 2015) }\end{array}$ & $\begin{array}{l}\text { Eldorado reef, } \\
\text { sidewall (le Roux } \\
2015)\end{array}$ \\
\hline$\phi\left(^{\circ}\right)$ & 42.3 & $\mathbf{2 7}$ & $\mathbf{3 4}$ \\
$S_{0}(\mathrm{MPa})$ & 4.42 & 13.48 & 18.8 \\
$C_{0}(\mathrm{MPa})$ & $\mathbf{2 0}$ & $\mathbf{4 4}$ & $\mathbf{6 8}$ \\
$T_{0}(\mathrm{MPa})$ & 3.91 & 16.52 & 19.22 \\
$m_{0}=C_{0} / T_{0}$ & 5.116 & 2.66 & 3.54 \\
$v$ & 0.25 & $\mathbf{0 . 2}$ & $\mathbf{0 . 2}$ \\
$1 /(2 v)$ & 2 & 2.5 & 2.5 \\
$E(\mathrm{GPa})$ & $\mathbf{5 . 5}$ & $\mathbf{7}$ & $\mathbf{7}$ \\
$\varepsilon_{T}(\%)$ & - & $\mathbf{0 . 1}$ & $\mathbf{0 . 1}$ \\
$\varepsilon_{T 0}(\%)$ & 0.071 & 0.236 & 0.275 \\
$\rho\left(\mathrm{kg} / \mathrm{m}^{3}\right)$ & $\mathbf{2 5 0 0}$ & $\mathbf{2 7 0 0}$ & $\mathbf{2 7 0 0}$ \\
\hline
\end{tabular}

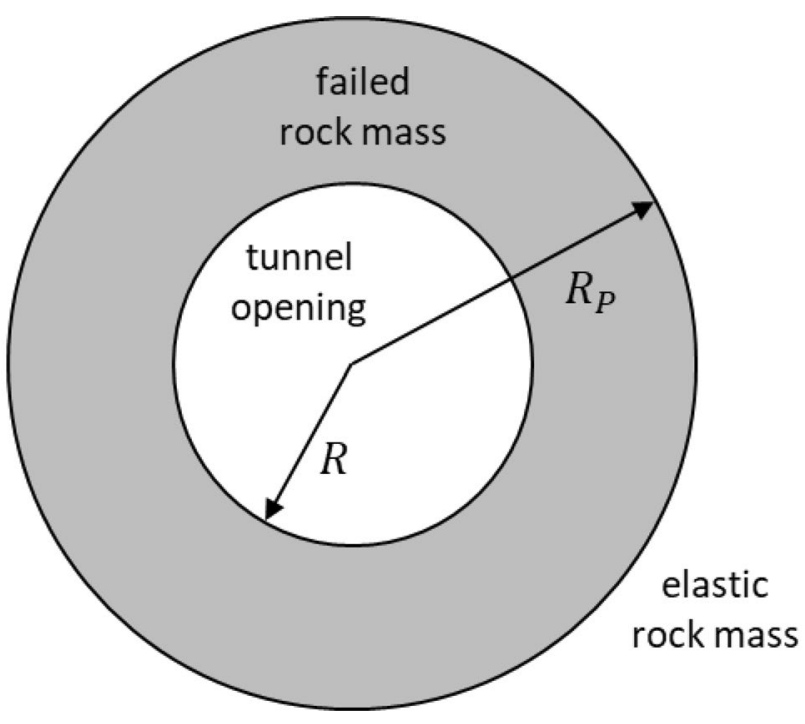

Fig. 11 Failed massive rock mass around a circular tunnel and notations

$$
\begin{aligned}
& \frac{R_{p}}{R}=\left\{\frac{2\left[\left(m_{0}-1\right)+a\right]}{\left(m_{0}+1\right)\left[\left(m_{0}-1\right) b+a\right]}\right\}^{\frac{1}{m_{0}-1}} \\
& \approx\left\{\frac{2\left[\left(m_{0}-1\right)+a\right]}{\left(m_{0}+1\right) a}\right\}^{\frac{1}{m_{0}-1}} .
\end{aligned}
$$

Assuming elastic brittle failure (Aydan et al. 2017) derived for the MC criterion, which also holds for the enriched strain criterion,

$\frac{R_{p}}{R}=\left\{\frac{\left(m_{0}+1\right)(1-b)}{\left(m_{0}-1\right)+a}\right\}^{\frac{1}{2}} \approx\left\{\frac{m_{0}+1}{\left(m_{0}-1\right)+a}\right\}^{\frac{1}{2}}$,

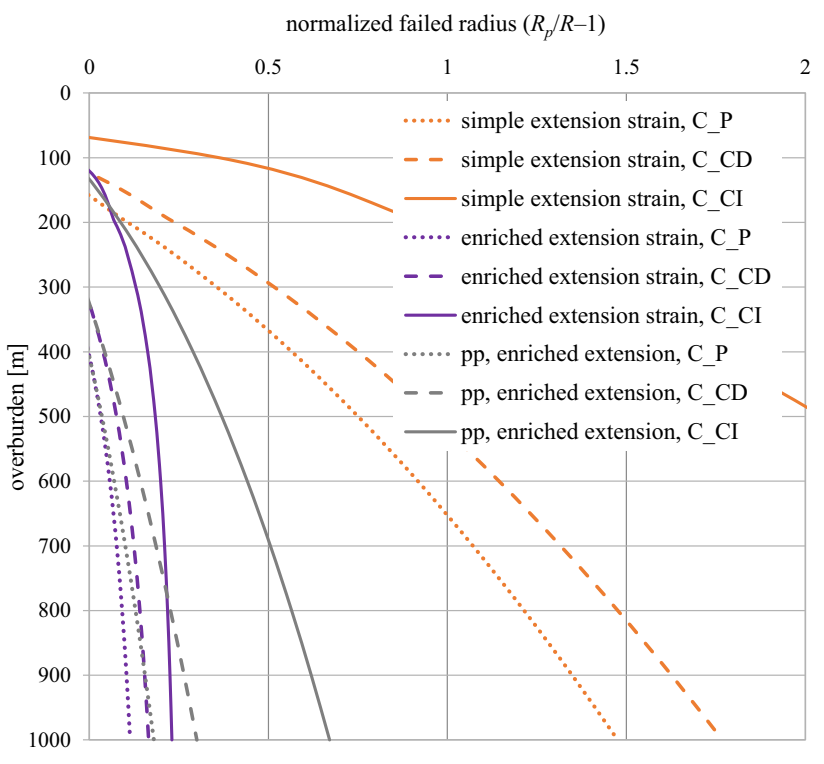

Fig. 12 Variations of normalized radius $R_{p} / R$ of the failed zone at the surface of a circular tunnel in good-quality rock mass data from Table $5\left(C_{p}=C_{0}, C_{\mathrm{CD}}=0.8 C_{P}\right.$, and $\left.C_{C I}=0.33 C_{P}\right)$ with overburden and $p_{i}=0$, estimated with the enriched extension strain criterion (equivalent to the $\mathrm{MC}$ criterion) and the simple extension strain criterion for different material parameters. The isotropic damage Eq. (27) with no cut-off is used with $m_{\mathrm{CI}}=m_{0}$ for the MC criterion and $m_{\mathrm{CI}}=1 / v$ for the simple extension strain criterion (the criteria are color-coded in the online publication)

and for the simple extension strain criterion,

$$
\begin{aligned}
\frac{R_{p}}{R}= & \left\{\frac{1+v}{E} \cdot \frac{p_{0}-p_{i}}{\varepsilon_{T}}\right\}^{\frac{1}{2}}=\left\{\frac{(1 / v+1)(1-b)}{a}\right\}^{\frac{1}{2}} \\
& \approx\left\{\frac{1 / v+1}{a}\right\}^{\frac{1}{2}} .
\end{aligned}
$$


Fig. 13 Planned open stope shape in white and predicted shapes of the failure domain in the hanging wall ( modified from le Roux 2015 with author's permission, color in online publication)
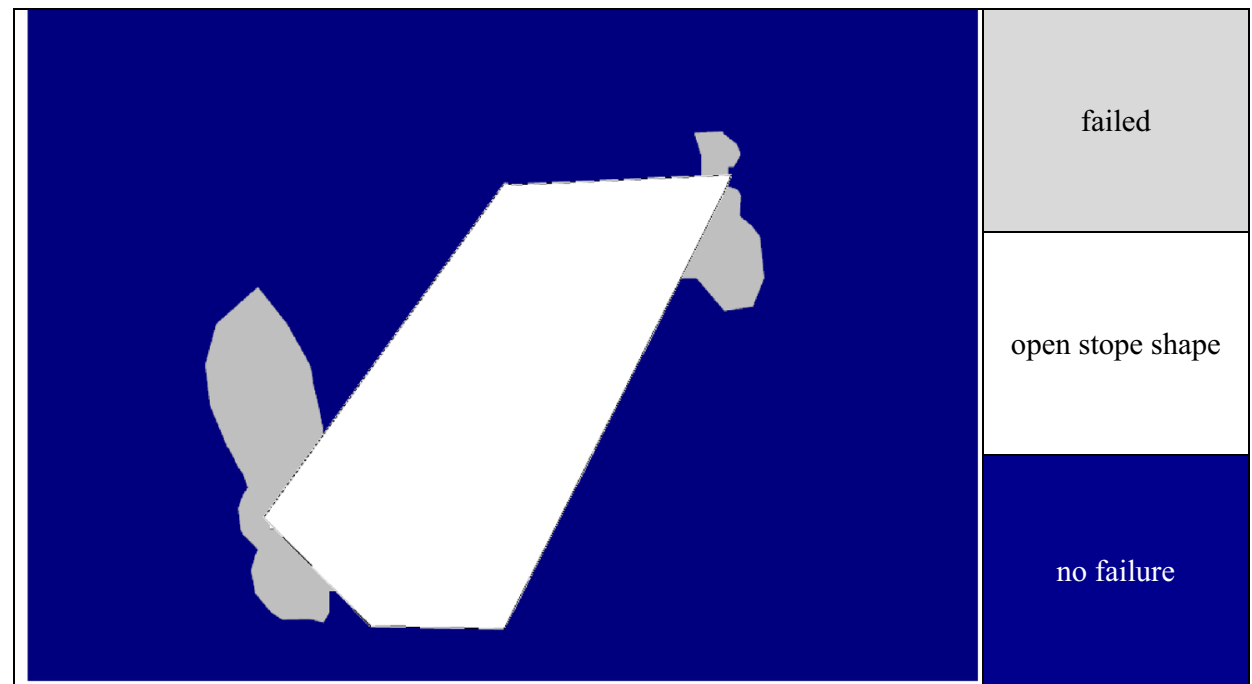

(a) Mohr-Coulomb, enriched extension strain criterion

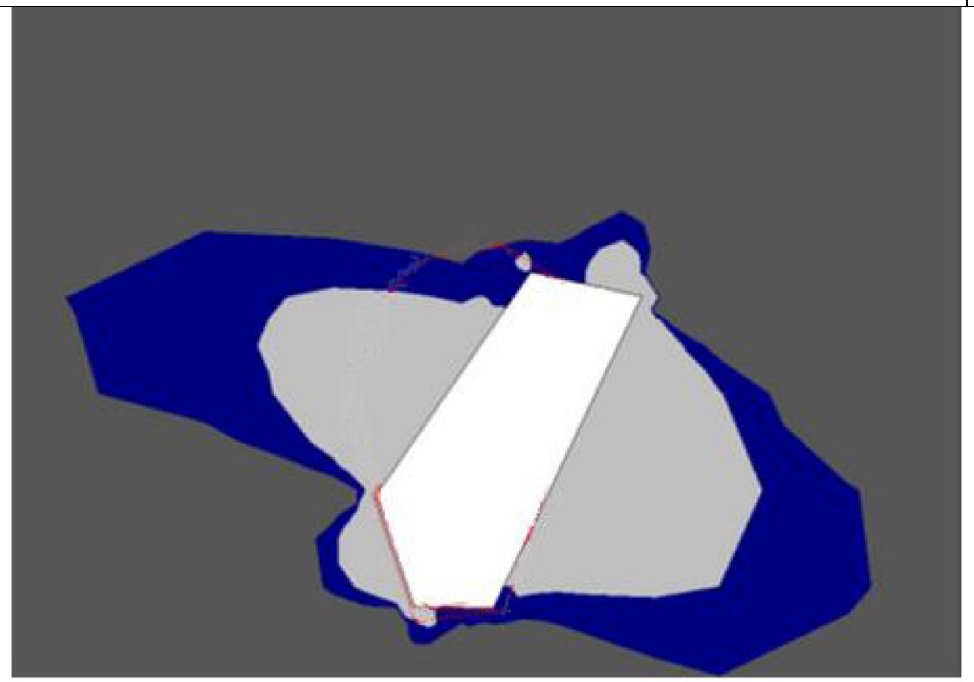

$\varepsilon_{I I I}<-\varepsilon_{T}$

failed

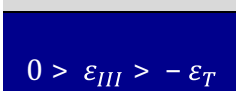

failure not expected

$\varepsilon_{I I I}>0$

failure impossible

(b) Simple extension strain criterion

The failed zone radii $R_{p}$ have been computed with an overburden of $\rho=2500 \mathrm{~kg} / \mathrm{m}^{3}, p_{i}=0$ and the data of goodquality rock mass (RMR greater than 60) from Table 6. In biaxial compression, the simple extension strain criterion allows only half the stress and strain compared to enriched extension strain criterion (MC criterion). Therefore, the simple extension strain criterion with MC theoretical strength data $m_{0}=m_{\text {CI }}$ predicts failure already at an overburden larger than $160 \mathrm{~m}$ for $C_{P}=C_{0}$, whereas the enriched extension strain criterion ( $\mathrm{MC}$ criterion) predicts failure at an overburden larger than $400 \mathrm{~m}$ in Fig. 12. The choice between the perfectly plastic (pp) and the brittle model makes only a minor difference. In Fig. 11, the same analysis is also shown for the upper and lower bound of long-term strength $C_{\mathrm{CD}}=0.8 C_{P}$ and $C_{C I}=0.33 C_{P}$, respectively. For $C_{C I}$, the simple extension strain criterion predicts failure at a reduced overburden of $80 \mathrm{~m}$. In addition, the radius $R_{p}$ of the failed rock mass is strongly over estimated by the simple extension strain criterion with respect to the enriched extension strain criterion (MC criterion) and even more to other strength criteria like the circumscribed Drucker-Prager criterion (Drucker and Prager 1952) and the triaxial Mogi-Coulomb criterion (Mogi 1971), which show even smaller failure radii (Singh et al. 2017). The difference between the simple extension strain criterion and the enriched extension strain criterion ( $\mathrm{MC}$ criterion) is considerably larger than the difference between the different damage thresholds, as expected from Fig. 2. The derivation of the MC criterion as an enriched extension strain criterion reflects the observation that the failure surface of rockburst is mostly associated with an extensional straining.

\subsubsection{Fracture Propagation Depth in Open Stopes}

The effect of fracture propagation depth in long hole open stopes failure is sometimes underestimated and relatively 
unknown. Actual data collected from 22 open stopes and the analysis thereof is used for numerical back analysis on the failure depth in (le Roux 2015) with the efficient Indirect Boundary Element Method software Map3D (Map3D International Ltd, https://www.map3d.com). The back calculation gives different rock mass data $C_{0}$ and $\phi_{0}$ for the hanging wall and the sidewall for all considered stress failure criteria. The data for the MC criterion are shown in Table 6 in bold together with the derived data. Additionally, the data for the simple extension strain criterion are given in Table 6.

The MC criterion predicts only a small fracture propagation into the hanging wall, Fig. 13a. This is also found for the other considered nonlinear stress failure criteria [Hoek-Brown criterion and five three-dimensional stress criteria based on it (le Roux 2015; le Roux and Brentley 2018)]. The shapes of the failure domain in the hanging wall were "similar" for the seven considered stress criteria. The actual observations were in the range of the predictions of the stress criteria, so that they show over and under predictions. The MC criterion was among the best and typically close the Hoek-Brown criterion. The Drucker-Prager criterion was excluded as not appropriate. Figure $13 \mathrm{~b}$ shows that the simple extension strain criterion overestimates the fracture propagation most significantly deeper into the hanging wall than observed and compared to the stress criteria.

The simple extension strain criterion and the CM criterion are also used in Borg (1983) to predict what mining levels will induce critically large loads in the roof of the stopes in cut and fill mining. The strong overestimation of fracture propagation by the simple extension strain criterion is addressed to the choice of a small critical strain $\varepsilon_{T}$ near the CI threshold in Borg (1983) and le Roux (2015), but could also be expected for the larger $\varepsilon_{T 0}$ from the failure envelope of the simple extension strain criterion (Fig. 2) and is in line with the analytical predictions for the circular tunnel in Fig. 12.

\section{Conclusions}

The simple extension strain criterion assumes that failure is only caused if a critical tensile strain is exceeded. The Poisson effect can produce negative strain and possibly failure in the direction of the major compressive stress and perpendicular to the minor stress even if all stresses are compressive. This leads to a strength differential (SD) effect, where the ratio between uniaxial compressive strength and tensile strength equals the Poisson's ratio. Assuming Hooke's law the strain criterion can be written in stress space. The simple extension strain criterion is presented in principal stress space as well as in principal strain space in comparison with the Mohr-Coulomb (MC) criterion. This shows that the simple extension strain criterion predicts the observed disking failure mode in equibiaxial compression but at only half the load compared to MC, which is too restrictive. As a consequence, the simple extension strain criterion predicts significantly larger failed domains in rock mass than observed in excavations. In biaxial tension, the criterion is unsafe with respect to the $\mathrm{MC}$ criterion. Therefore, the use of the simple extension strain criterion cannot be recommended for quantitative reasons.

The observation that extension fractures can show some amount of shear contribution to failure suggests to add a weighted amount of shear to the extension strain. The Shear weight factor can be chosen as such that the enriched extension strain criterion is represented by the same function as the $\mathrm{MC}$ criterion and both criteria predict the same strength if the same data are used for both. 100 years after the wellknown MC strength theory was established in 1900, it is still the most widely in rock engineering (Yu 2002). Therefore, the enriched extension strain criterion deserves the same recommendation as the $\mathrm{MC}$ criterion for application to rock and other cohesive-frictional geomaterials. The 2D plots of the failure envelopes show that the corners of uniaxial compressive (positive) stress in stress space correspond to corners of biaxial strain with a negative component in strain space, which indicates extension strain. This explains why extension failure happens in compressive stress.

The MC parameters obtained from shear tests have a tendency to overestimate the tensile strength leading to some inconsistencies between theoretical and measured uniaxial strength data. A similar inconsistency is observed for the enriched extension strain criterion and may originate from the different crack densities in direct and indirect extension. Therefore, it is recommended to use the enriched extension strain criterion with the measured strength data or to use a cut-off.

Brittle materials are characterized by heterogeneous microstructures that cause a random distribution of flaws like voids and cracks. These concentrate extensional strain locally and initiate fracture in both tensile and compressive stress fields. Therefore, the most feasible fracture propagation direction is always orthogonal to the maximum extensional strain. In tensile stress fields, extensional strain is realized directly in the loading direction, whereas in compressive stress fields, extensional strain is realized indirectly and orthogonal to the loading direction through a complex interaction of micromechanical processes, which depend on the heterogeneity of the microstructure (Klerck et al. 2004). In compression tests, the indirect extension by the Poisson effect produces an order more cracks at lower strains compared with the direct extension in tensile tests (Ren et al. 2018). Therefore, different damage models in tension and compression may be needed. For the compressive damage model, the enriched extension strain criterion or, in other words, the MC criterion can be proposed as threshold 
surface for crack initiation and crack damage, and as failure surface at peak stress or ultimate extension strain. For a simple crack damage model, a tension or extension cut-off at the crack initiation threshold is recommended. The crack damage models have not yet been fully developed and may need the coupling with plastic and creep damage models.

Acknowledgements The author thanks Ömer Aydan, Jesús G. Martínez-Figueroa, Prasoon Garg, Melih Geniş, Vladimir Kolupaev, Joseph F. Labuz, Jacky Mazars, Matthew A. Perras, and Jacob le Roux for supporting input in form of pictures, data or discussion. The author would like to acknowledge in particular Amoussou C. Adoko, Florian Amann, and the three reviewers who read the manuscript and made valuable suggestions for improvement.

Funding Open Access funding enabled and organized by Projekt DEAL.

\section{Declarations}

Conflict of interest The author did not receive support from any organization for the submitted work. The author has no relevant financial or non-financial interests to disclose.

Open Access This article is licensed under a Creative Commons Attribution 4.0 International License, which permits use, sharing, adaptation, distribution and reproduction in any medium or format, as long as you give appropriate credit to the original author(s) and the source, provide a link to the Creative Commons licence, and indicate if changes were made. The images or other third party material in this article are included in the article's Creative Commons licence, unless indicated otherwise in a credit line to the material. If material is not included in the article's Creative Commons licence and your intended use is not permitted by statutory regulation or exceeds the permitted use, you will need to obtain permission directly from the copyright holder. To view a copy of this licence, visit http://creativecommons.org/licenses/by/4.0/.

\section{References}

Al Mandalawi M, Sabry M, Sabry M (2020) Initiation mechanism of extension strain of rock mine slopes. In: Adam Bezvijen, Wittke W, Poulos H, Shehata H (eds) Latest advancements in underground structures and geological engineering. GeoMEast 2019. Sustainable Civil Infrastructures. Springer, Cham, pp 52-64

Alejano LR, Alonso E (2005) Considerations of the dilatancy angle in rocks and rock masses. Int J Rock Mech Min Sci 42:481-507. https://doi.org/10.1016/j.ijrmms.2005.01.003

Amann F, Button EA, Evans KF et al (2011) Experimental study of the brittle behavior of clay shale in rapid unconfined compression. Rock Mech Rock Eng 44:415-430. https://doi.org/10.1007/ s00603-011-0156-3

Aubertin M, Li L, Simon R (2000) A multiaxial stress criterion for short- and long-term strength of isotropic rock media. Int J Rock Mech Min Sci 37:1169-1193. https://doi.org/10.1016/S13651609(00)00047-2

Aydan Ö, Geniş M (2010) A unified analytical solution for stress and strain fields about radially symmertric openings in elasto-plastic rock with the consideration of support system and long-term properties of surrounding rock. Int J Min Miner Process 1:1-32
Aydan Ö, Geniş M, Akagi T, Kawamoto T (2017) Assessment of susceptibility of rock bursting in tunnelling in hard rocks. In: Adachi T, Tateyama K, Kimura M (eds) Modern tunneling science and technology, vol 1, 1st edn. Routledge, London, pp 391-396

Baricco M, Baser TA, Das J, Eckert JH (2009) Correlation between Poisson ratio and Mohr-Coulomb coefficient in metallic glasses. J Alloys Compd 483:125-131. https://doi.org/10.1016/j.jallcom. 2008.07.213

Barsanescu P, Sandovici A, Serban A (2018) Mohr-Coulomb criterion with circular failure envelope, extended to materials with strength-differential effect. Mater Des 148:49-70. https://doi.org/ 10.1016/j.matdes.2018.03.043

Barton NR (2020) Unconventional exploration of failure modes in rock and rock masses. In: ISRM International SymposiumEUROCK 2020 June 14-19, 2020 physical event not held. p ISRM-EUROCK-2020-204

Barton N, Shen B (2017) Risk of shear failure and extensional failure around over-stressed excavations in brittle rock. J Rock Mech Geotech Eng 9:210-225. https://doi.org/10.1016/j.jrmge.2016. 11.004

Barton N, Shen B (2018) Extension strain and rock strength limits for deep tunnels, cliffs, mountain walls and the highest mountains. Rock Mech Rock Eng 51:3945-3962. https://doi.org/10.1007/ s00603-018-1558-2

Basu A, Mishra DA, Roychowdhury K (2013) Rock failure modes under uniaxial compression, Brazilian, and point load tests. Bull Eng Geol Environ 72:457-475. https://doi.org/10.1007/ s10064-013-0505-4

Bauch E, Lempp C (2004) Rock splitting in the surrounds of underground openings: An experimental approach using triaxial extension tests. In: Charlier R, Hack R, Azzam R (eds) Engineering geology for infrastructure planning in Europe. Springer, Berlin, Heidelberg, pp 244-254

Beierlein G (1985) Festigkeitsverhalten keramischer Werkstoffe unter mehrachsiger Belastung. Hermsdorfer Tech Mitteilungen 25:2116-2122

Bieniawski ZT (1967) Mechanism of brittle fracture of rock. Parts 1-3. Int J Rock Mech Min Sci Geomech Abstr 4:395-430. https://doi. org/10.1016/0148-9062(67)90030-7

Borg T (1983) Prediction of rock failures in mines, with application to the Näsliden mine in northern Sweden. Luleå University of Technology

Brace WF (1960) An extension of the Griffith theory of fracture to rocks. J Geophys Res 65:3477-3480. https://doi.org/10.1029/ JZ065i010p03477

Brace WF, Paulding BW, Scholz C (1966) Dilatancy in the fracture of crystalline rocks. J Geophys Res 71:3939-3953. https://doi.org/ 10.1029/JZ071i016p03939

Bridgman PW (1912) V. Breaking tests under hydrostatic pressure and conditions of rupture. Lond Edin Dublin Philos Mag J Sci 24:63-80. https://doi.org/10.1080/14786440708637310

Bridgman PW (1938) Reflections on rupture. J Appl Phys 9:517-528. https://doi.org/10.1063/1.1710449

Brown ET, Trollope DH (1967) The failure of linear brittle materials under effective tensile stress. Felsmechanik Und Ingenieurgeologie, Rock Mech Eng Geol 5:229-241

Burzyński WT (1928) Studium nad hipotezami wytężenia [Study on material effort hypotheses]. Doctoral Dissertation, Academy of Technical Sciences, Lwów

Burzyński W (1929) Ueber Die Anstrengungshypothesen. Schweizerische Bauzeitung 94:259-262

Buyukozturk O (1977) Nonlinear analysis of reinforced concrete structures. Comput Struct 7:149-156. https://doi.org/10.1016/00457949(77)90069-4 
Carino NJ, Slate FO (1976) Limiting tensile strain criterion for failure of concrete. ACI J Proc 73:160-165. https://doi.org/10.14359/ 11065

Chaboche J-L (1993) Development of continuum damage mechanics for elastic solids sustaining anisotropic and unilateral damage. Int J Damage Mech 2:311-329. https://doi.org/10.1177/10567 8959300200401

Chakraborty S, Bisai R, Palaniappan SK, Pal SK (2019) Failure modes of rocks under uniaxial compression tests: an experimental approach. J Adv Geotech Eng 2:1-8. https://doi.org/10.5281/ zenodo. 3461773

Christensen RM (2013) The theory of materials failure. Oxford University Press, Oxford

Clausen J, Damkilde L, Andersen L (2006) Efficient return algorithms for associated plasticity with multiple yield planes. Int J Numer Methods Eng 66:1036-1059. https://doi.org/10.1002/nme.1595

Comanici AM, Barsanescu PD (2018) Modification of Mohr's criterion in order to consider the effect of the intermediate principal stress. Int J Plast 108:40-54. https://doi.org/10.1016/j.jplas.2018.04. 010

Contrafatto L, Cuomo M (2007) Comparison of two forms of strain decomposition in an elastic-plastic damaging model for concrete. Model Simul Mater Sci Eng 15:S405-S423. https://doi.org/10. 1088/0965-0393/15/4/S07

Cotterell B (1972) Brittle fracture in compression. Int J Fract Mech 8:195-208. https://doi.org/10.1007/BF00189782

Coulomb CA (1773) Essai sur une application des règles de maximis \& minimis à quelques problèmes de statique, relatifs à l'architecture. Mém Math Phys Present à l'Acád R des Sci par Divers Savantes, Lûs Dans Ses Assem 7:343-387

Damjanac B, Fairhurst C (2010) Evidence for a long-term strength threshold in crystalline rock. Rock Mech Rock Eng 43:513-531. https://doi.org/10.1007/s00603-010-0090-9

Daraei A, Zare S (2018) A new strain-based criterion for evaluating tunnel stability. Geomech Eng 16:205-215. https://doi.org/10. 12989/gae.2018.16.2.205

de Coulomb C-A (1776) Essai sur une application des règles des maximis \& minimis à quelques problèmes de statique relatifs à l'architecture. Mém Math l'Acad R des Sci Paris 7:343-387

Diederichs MS (2003) Rock fracture and collapse under low confinement conditions. Rock Mech Rock Eng 36:339-381. https://doi. org/10.1007/s00603-003-0015-y

Drucker DC, Prager W (1952) Soil mechanics and plastic analysis or limit design. Q Appl Math 10:157-165

Dyskin AV (1998) Stress fluctuation mechanism of mesocrack growth, dilatancy and failure of heterogeneous materials in uniaxial compression. Heron 43:137-158

Eberhardt E, Stead D, Stimpson B, Read RS (1998) Identifying crack initiation and propagation thresholds in brittle rock. Can Geotech J 35:222-233. https://doi.org/10.1139/t97-091

Eberhardt E, Stead D, Stimpson B (1999) Quantifying progressive pre-peak brittle fracture damage in rock during uniaxial compression. Int J Rock Mech Min Sci 36:361-380. https://doi.org/ 10.1016/S0148-9062(99)00019-4

Escartín J, Hirth G, Evans B (1997) Nondilatant brittle deformation of serpentinites: Implications for Mohr-Coulomb theory and the strength of faults. J Geophys Res Solid Earth 102:28972913. https://doi.org/10.1029/96JB02792

Ewy RT (1998) Wellbore stability predictions using a modified Lade criterion. In: SPE/ISRM Rock Mechanics in Petroleum Engineering. SPE, Trondheim

Eyre JR, Nasreddin HS (2013) Tension strain failure criterion for concrete. Mag Concr Res 65:1303-1314. https://doi.org/10. 1680/macr.13.00171

Fairhurst C, Cook N (1966) The of maximum phenomenon of rock splitting parallel to the direction compression in the neighbourhood of a surface. In: 1st ISRM Congress, 25 September-1 October, Lisbon, Portugal. International Society for Rock Mechanics and Rock Engineering

Föppl A (1900) Die Abhängigkeit der Bruchgefahr von der Art des Spannungszustandes. Mitth Aus Dem Mech Lab Der K Tech Hochschule München 27:1-35

Fujii Y, Kiyama T, Ishijima Y, Kodama J (1998) Examination of a rock failure criterion based on circumferential tensile strain. Pure Appl Geophys 152:551-577. https://doi.org/10.1007/ s000240050167

Gao M, Li T, Meng L et al (2018) Identifying crack initiation stress threshold in brittle rocks using axial strain stiffness characteristics. J Mt Sci 15:1371-1382. https://doi.org/10.1007/ s11629-018-4847-z

Garg P, Pandit B, Mishra B (2018) Investigation of the failure mode of intact rock in biaxial compression tests. In: 52nd U.S. Rock Mechanics/Geomechanics Symposium. American Rock Mechanics Association, Seattle, Washington

Gesualdo A, Monaco M (2015) Constitutive behaviour of quasi-brittle materials with anisotropic friction. Lat Am J Solids Struct 12:695-710. https://doi.org/10.1590/1679-78251345

Griffith AA (1924) The theory of rupture. In: Biereno CB, Burgers JM (eds) Proceedings of the 1st International Congress on Applied Mechanics. Tech. Boekhandel en Drukkerij. J. Waltman Jr., Delft, pp 54-63

Griggs D, Handin J (1960) Observations on fracture and a hypothesis of earthquakes. In: Griggs D, Handin J (eds) Rock Deformation (A Symposium). Geological Society of America, New York, pp 347-364

Hajiabdolmajid V, Kaiser PK, Martin CD (2002) Modelling brittle failure of rock. Int J Rock Mech Min Sci 39:731-741. https:// doi.org/10.1016/S1365-1609(02)00051-5

He J, Li M (2010) Cellular automata to simulate split of quasi-brittle materials. In: 2010 International Conference on E-Product E-Service and E-Entertainment. IEEE, pp 1-4

Heidarzadeh S, Saeidi A, Rouleau A (2021) The damage-failure criteria for numerical stability analysis of underground excavations: a review. Tunn Undergr Sp Technol 107:103633. https:// doi.org/10.1016/j.tust.2020.103633

Hoek E (1999) Support for very weak rock associated with faults and shear zones. A.A. Balkema, Rotterdam, Brookfield

Hoek E, Brown ET (1980) Underground excavations in rock. Institute of Mining and Metallurgy, London

Hoek E, Brown ET (1997) Practical estimates of rock mass strength. Int J Rock Mech Min Sci 34:1165-1186. https://doi.org/10. 1016/S1365-1609(97)80069-X

Hoek E, Martin CD (2014) Fracture initiation and propagation in intact rock-a review. J Rock Mech Geotech Eng 6:287-300. https://doi.org/10.1016/j.jrmge.2014.06.001

Horii H, Nemat-Nasser S (1986) Brittle failure in compression: splitting faulting and brittle-ductile transition. Philos Trans R Soc Lond Ser Math Phys Sci 319:337-374. https://doi.org/10.1098/ rsta.1986.0101

Huang H, Fan P, Li J et al (2016) A theoretical explanation for rock core disking in triaxial unloading test by considering local tensile stress. Acta Geophys 64:1430-1445. https://doi.org/10.1515/ acgeo-2016-0068

Hudson JA, Crouch SL, Fairhurst C (1972) Soft, stiff and servo-controlled testing machines: a review with referenceto rock failure. Eng Geol 6:155-189. https://doi.org/10.1016/0013-7952(72) 90001-4

Iskander M, Shrive N (2018) Fracture of brittle and quasi-brittle materials in compression: A review of the current state of knowledge and a different approach. Theor Appl Fract Mech 97:250-257. https://doi.org/10.1016/j.tafmec.2018.08.014 
Jakel R (1993) Ein Vorschlag für ein globales Mehrachsigkeitskriterium für keramische Werkstoffe auf Basis gewichteter Verzerrungen. Institutsmitteilungen des IMW 18:73-82. https://doi.org/ 10.21268/20161114-153224

Jager AJ, Ryder JA (eds) (2002) A Textbook on rock mechanics for tabular hard rock mines. Safety in Mines Research Advisory Committee (SIMRAC), Johannesburg

Jia S, Zhao Z, Wu G et al (2020) A coupled elastoplastic damage model for clayey rock and its numerical implementation and validation. Geofluids 2020:1-14. https://doi.org/10.1155/2020/9853782

Karavelić E, Ibrahimbegovic A, Dolarević S (2019) Multi-surface plasticity model for concrete with 3D hardening/softening failure modes for tension, compression and shear. Comput Struct 221:74-90. https://doi.org/10.1016/j.compstruc.2019.05.009

Kirsch EG (1898) Die Theorie der Elastizität und die Bedürfnisse der Festigkeitslehre. Zeitschrift des Vereines deutscher Ingenieure 42:797-807

Klerck PA, Sellers EJ, Owen DRJ (2004) Discrete fracture in quasibrittle materials under compressive and tensile stress states. Comput Methods Appl Mech Eng 193:3035-3056. https://doi. org/10.1016/j.cma.2003.10.015

Kolari K (2019) Modeling splitting and spalling of columnar ice compressed biaxially: The role of crack nucleation. JGR Solid Earth 124:3271-3287. https://doi.org/10.1029/2018113017032

Kolupaev VA (2018) Equivalent stress concept for limit state analysis. Springer International Publishing, Cham

Korinets A, Alehossein H (2002) On the initial non-linearity of compressive stress-strain curves for intact rock. Rock Mech Rock Eng 35:319-328. https://doi.org/10.1007/s00603-002-0030-4

Kotsovos MD (1979) Fracture processes of concrete under generalised stress states. Matériaux Constr 12:431-437. https://doi.org/10. 1007/BF02476287

Krabbenhøft K, Lyamin AV, Sloan SW (2007) Three-dimensional Mohr-Coulomb limit analysis using semidefinite programming. Commun Numer Methods Eng 24:1107-1119. https://doi.org/ $10.1002 / \mathrm{cnm} .1018$

Kuijpers J (2000) Fracturing around highly stressed excavations in brittle rock. J S Afr Inst Min Metall 100:325-331. https://hdl.handle. net/10520/AJA0038223X_2597

Kunz J (2011) The case for strain based design. Kunststoffe Int 28-32

Kupfer H, Hilsdorf HK, Rusch H (1969) Behavior of concrete under biaxial stresses. ACI J Proc 66:656-666. https://doi.org/10. $14359 / 7388$

Kwaśniewski M, Takahashi M (2010) Strain-based failure criteria for rocks: State of the art and recent advances. In: Zhao J, Labiouse V, Dudt J-P, Mathier J-F (eds) Rock mechanics in civil and environmental engineering. CRC Press, Taylor \& Francis, London, London, pp 45-56

Labuz JF, Zang A (2012) Mohr-Coulomb failure criterion. Rock Mech Rock Eng 45:975-979. https://doi.org/10.1007/ s00603-012-0281-7

Lau JSO, Chandler NA (2004) Innovative laboratory testing. Int J Rock Mech Min Sci 41:1427-1445. https://doi.org/10.1016/j.ijrmms. 2004.09.008

le Roux PJ (2015) Measurement and prediction of dilution in a gold mine operating with open stoping mining methods. $\mathrm{PhD}$ thesis, University of the Witwatersrand, Johannesburg

le Roux PJ (2018) Brentley KR (2018) Simulation of fracture propagation depth and failure in long hole open stoping. In: Litvinenko V (ed) ISRM Regional Symposium-EUROCK 2018. International Society for Rock Mechanics and Rock Engineering. CRC Press/ Balkema, Saint Petersbrug, pp 22-26

Lelović S, Vasović D, Stojić D (2019) Determination of the MohrCoulomb material parameters for concrete under indirect tensile test. Teh Vjesn Tech Gaz 26:412-419. https://doi.org/10.17559/ TV-20180612090311
Li D, Wong LNY (2013) The Brazilian disc test for rock mechanics applications: review and new insights. Rock Mech Rock Eng 46:269-287. https://doi.org/10.1007/s00603-012-0257-7

Li X, Wu Z, Takahashi M, Yasuhara K (2000) An experimental study on strain-based failure criteria of brittle materials. J Appl Mech 3:387-394. https://doi.org/10.2208/journalam.3.387

Li X, Li C, Li Y, Zhang P (2020) Research of transitional failure mode as damage evolution in rock wall. Adv Civ Eng 2020:1-12. https://doi.org/10.1155/2020/8864074

Lilliu G, van Mier JGM (2001) Experimental investigation of fracture processes in concrete cylinders subjected to torsion. In: Mazars J, Pijaudier-Cabot G, de Borst R, van Mier JGM (eds) Fracture Mechanics of Concrete Structures: Proceedings of the Fourth International Conference on Fracture Mechanics of Concrete and Concrete Structures, Cachan, France, 28 May-1 June 2001. Swets \& Zeitlinger, Lisse, pp 395-402

Lógó BA, Vásárhelyi B (2019) Estimation of the Poisson's rate of the intact rock in the function of the rigidity. Period Polytech Civ Eng 63:1030-1037. https://doi.org/10.3311/PPci.14946

Louchnikov V (2011) Simple calibration of the extension strain criterion for its use in numerical modelling. In: Potvin Y (ed) Proceedings of the fourth international seminar on strategic versus tactical approaches in mining. Australian Centre for Geomechanics, Perth, pp 85-96

Lubarda VA, Krajcinovic D, Mastilovic S (1994) Damage model for brittle elastic solids with unequal tensile and compressive strengths. Eng Fract Mech 49:681-697. https://doi.org/10.1016/ 0013-7944(94)90033-7

Maier-Leibnitz H (1928) Beitrag zur Frage der tatsächlichen Tragfähigkeit einfacher und durchlaufender Balkenträger aus Baustahl St 37 und Holz. Die Bautechnik 6:11-14, 27-31

Martin CD, Chandler NA (1994) The progressive fracture of Lac du Bonnet granite. Int J Rock Mech Min Sci Geomech Abstr 31:643-659. https://doi.org/10.1016/0148-9062(94)90005-1

Martin CM, Makrodimopoulos A (2008) Finite-element limit analysis of Mohr-Coulomb materials in 3D using semidefinite programming. J Eng Mech 134:339-347. https://doi.org/10.1061/(ASCE) 0733-9399(2008)134:4(339)

Martin CD, Stimpson B (1994) The effect of sample disturbance on laboratory properties of Lac du Bonnet granite. Can Geotech J 31:692-702. https://doi.org/10.1139/t94-081

Martin CD, Kaiser PK, McCreath DR (1999) Hoek-Brown parameters for predicting the depth of brittle failure around tunnels. Can Geotech J 36:136-151. https://doi.org/10.1139/t98-072

Mazars J (1986) A description of micro- and macroscale damage of concrete structures. Eng Fract Mech 25:729-737. https://doi.org/ 10.1016/0013-7944(86)90036-6

Mazars J, Hamon F, Grange S (2015) A new 3D damage model for concrete under monotonic, cyclic and dynamic loadings. Mater Struct 48:3779-3793. https://doi.org/10.1617/ s11527-014-0439-8

Mogi K (1971) Fracture and flow of rocks under high triaxial compression. J Geophys Res 76:1255-1269. https://doi.org/10.1029/ JB076i005p01255

Mohr CO (1900) Welche Umstände bedingen die Elastizitätsgrenze und den Bruch eines Materials? Zeitschrift des Vereines deutscher Ingenieure 44:1524-1530 and 1572-1577

Muralha J, Grasselli G, Tatone B et al (2014) ISRM suggested method for laboratory determination of the shear strength of rock joints: revised version. Rock Mech Rock Eng 47:291-302. https://doi.org/10.1007/s00603-013-0519-z

Murrell SAF (1963) A criterion for brittle fracture of rocks and concrete under triaxial stress and the effect of pore pressure on the criterion. In: Fairhurst C (ed) Proceedings of the 5th Rock Mechanics Symposium held at the University of Minnesota, May 1962. Oxford, Pergamon, London, New York, pp 563-577 
Nádai A (1950) Theory of flow and fracture of solids, 2nd edn. McGraw-Hill, New York

Nadler P (1989) Beitrag zur Charakterisierung und Berücksichtigung des spezifisch keramischen Festigkeitsverhaltens. Doctoral Dissertation, Bergakademie Freiberg

Newman JB, Kotsovos MD (1977) Behavior of concrete under multiaxial stress. ACI J Proc 74:443-446. https://doi.org/10.14359/ 11023

Nguyen GD, Houlsby GT (2008) A coupled damage-plasticity model for concrete based on thermodynamic principles: Part I: model formulation and parameter identification. Int J Numer Anal Methods Geomech 32:353-389. https://doi.org/10.1002/nag. 627

Nicksiar M, Martin CD (2012) Evaluation of methods for determining crack initiation in compression tests on low-porosity rocks. Rock Mech Rock Eng 45:607-617. https://doi.org/10.1007/ s00603-012-0221-6

Panthee S, Khanal M, Singh TN (2016) Geotechnical and geomechanical characteristics of the rocks along tunnel of Kulekhani III hydro-electric project. J Nepal Geol Soc 50:39-50. https://doi. org/10.3126/jngs.v50i1.22852

Paraskevopoulou C, Perras M, Diederichs M et al (2017) The three stages of stress relaxation - Observations for the time-dependent behaviour of brittle rocks based on laboratory testing. Eng Geol 216:56-75. https://doi.org/10.1016/j.enggeo.2016.11.010

Pepe G, Mineo S, Pappalardo G, Cevasco A (2018) Relation between crack initiation-damage stress thresholds and failure strength of intact rock. Bull Eng Geol Environ 77:709-724. https://doi.org/ 10.1007/s10064-017-1172-7

Perras MA (2014) Understanding and predicting excavation damage in sedimentary rocks: a continuum based approach. $\mathrm{PhD}$ thesis, Queen's University, Kingston. https://hdl.handle.net/1974/8594

Perras MA, Diederichs MS (2014) A review of the tensile strength of rock: concepts and testing. Geotech Geol Eng 32:525-546. https://doi.org/10.1007/s10706-014-9732-0

Perras MA, Diederichs MS (2016) Predicting excavation damage zone depths in brittle rocks. J Rock Mech Geotech Eng 8:60-74. https://doi.org/10.1016/j.jrmge.2015.11.004

Perras MA, Diederichs MS, Amann F (2012) Fracture initiation and propagation in the Quintner limestone. In: 46th U.S. Rock Mechanics/Geomechanics Symposium, June 24-27. American Rock Mechanics Association, Chicago

Pietruszczak S, Mroz Z (2001) On failure criteria for anisotropic cohesive-frictional materials. Int J Numer Anal Methods Geomech 25:509-524. https://doi.org/10.1002/nag.141

Pouragha M, Wan R, Eghbalian M (2019) Critical plane analysis for interpreting experimental results on anisotropic rocks. Acta Geotech 14:1215-1225. https://doi.org/10.1007/s11440-018-0683-0

Rahjoo M, Woo K-S, Eberhardt E (2016) Stress-induced spalling analysis of extraction level pillars using a 3-D extensional strain failure criterion. 50th US Rock Mechanics/Geomechanics Symposium, ARMA 2016, June. American Rock Mechanics Association, Houston, pp 26-29

Ren J, Tian Z, Bu J (2018) Simulating tensile and compressive failure process of concrete with a user-defined bonded-particle model. Int J Concr Struct Mater 12:56. https://doi.org/10.1186/ s40069-018-0292-1

Reynolds O (1885) On the dilatancy of media composed of rigid particles in contact. With experimental illustrations. Lond Edinb Dublin Philos Mag J Sci 20:469-481. https://doi.org/10.1080/ 14786448508627791

Riyad ASM, Rokonuzzaman M, Sakai T (2020) Effect of using different approximation models to the exact Mohr-Coulomb material model in the FE simulation of Anchor Foundations in sand. Int J Geo Eng 11:11. https://doi.org/10.1186/s40703-020-00119-y
Robinson GS (1967) Behavior of concrete in biaxial compression. J Struct Div 93:71-86. https://doi.org/10.1061/JSDEAG.0001631

Scholz CH, Boitnott G, Nemat-Nasser S (1986) The Bridgman ring paradox revisited. Pure Appl Geophys PAGEOPH 124:587-599. https://doi.org/10.1007/BF00877217

Sengani F (2020) A simple time-dependent chart of extension fracture initiation within brittle homogenous and heterogeneous rock pillars in hard rock mining. Geotech Geol Eng 38:2803-2833. https://doi.org/10.1007/s10706-020-01188-7

Shen B, Barton N (2018) Rock fracturing mechanisms around underground openings. Geomech Eng 16:35-47. https://doi.org/10. 12989/gae.2018.16.1.035

Shen J, Priest SD, Karakus M (2012) Determination of Mohr-Coulomb shear strength parameters from generalized Hoek-Brown criterion for slope stability analysis. Rock Mech Rock Eng 45:123129. https://doi.org/10.1007/s00603-011-0184-z

Singh A, Rao KS, Ayothiraman R (2017) Effect of intermediate principal stress on cylindrical tunnel in an elasto-plastic rock mass. Procedia Eng 173:1056-1063. https://doi.org/10.1016/j.proeng. 2016.12.185

Sivakugan N, Das BM, Lovisa J, Patra CR (2014) Determination of c and $\varphi$ of rocks from indirect tensile strength and uniaxial compression tests. Int J Geotech Eng 8:59-65. https://doi.org/10. 1179/1938636213Z.00000000053

Stacey TR (1981) A simple extension strain criterion for fracture of brittle rock. Int J Rock Mech Min Sci Geomech Abstr 18:469_ 474. https://doi.org/10.1016/0148-9062(81)90511-8

Stacey TR, Terbrugge PJ, Keyter GJ, Xianbin Y (2003a) Extension strain - a new concept in open pit slope stability, and its use in the explanation of two slope failures. In: AuSIMM-Fifth Large Open Pit Mining Conference, 3-5 November 2003, Kalgoorlie, pp 259-266

Stacey TR, Xianbin Y, Armstrong R, Keyter GJ (2003b) New slope stability considerations for deep open pit mines. J S Afr Inst Min Metall 103:373-389. https://hdl.handle.net/10520/AJA00 38223X_2808

Stimpson B, Chen R (1993) Measurement of rock elastic moduli in tension and in compression and its practical significance. Can Geotech J 30:338-347. https://doi.org/10.1139/t93-028

Sundaram PN, Corrales JM (1980) Brazilian tensile strength of rocks with different elastic properties in tension and compression. Int J Rock Mech Min Sci Geomech Abstr 17:131-133. https://doi. org/10.1016/0148-9062(80)90265-X

Taheri A, Zhang Y, Munoz H (2020) Performance of rock crack stress thresholds determination criteria and investigating strength and confining pressure effects. Constr Build Mater 243:118263. https://doi.org/10.1016/j.conbuildmat.2020.118263

Tham LG, Liu H, Tang CA et al (2005) On Tension Failure of 2-D Rock Specimens and Associated Acoustic Emission. Rock Mech Rock Eng 38:1-19. https://doi.org/10.1007/s00603-004-0031-6

Turk N, Dearman WR (1986) Estimation of friction properties of rocks from deformation measurements. In: The 27th U.S. Symposium on Rock Mechanics (USRMS), 23-25 June. American Rock Mechanics Association, Tuscaloosa, Alabama, pp 93-99

Vermeer PA, de Borst R (1984) Non-associated plasticity for soils, concrete and rock. Heron 29:1-64. http://resolver.tudelft.nl/uuid: 4ee188ab-8ce0-4df3-adf5-9010ebfaabf0

Wawersik WR, Fairhurst C (1970) A study of brittle rock fracture in laboratory compression experiments. Int J Rock Mech Min Sci Geomech Abstr 7:561-575. https://doi.org/10.1016/01489062(70)90007-0

Wei L, Liu Q, Liu X (2018) An improved crack initiation stress criterion for brittle rocks under confining stress. IOP Conf Ser Earth Environ Sci 170:022141. https://doi.org/10.1088/1755-1315/ 170/2/022141 
Wesseloo J, Stacey TR (2016) A reconsideration of the extension strain criterion for fracture and failure of rock. Rock Mech Rock Eng 49:4667-4679. https://doi.org/10.1007/s00603-016-1059-0

Wojciechowski M (2018) A note on the differences between DruckerPrager and Mohr-Coulomb shear strength criteria. Stud Geotech Mech 40:163-169. https://doi.org/10.2478/sgem-2018-0016

Xue L, Qin S, Sun Q et al (2014) A study on crack damage stress thresholds of different rock types based on uniaxial compression tests. Rock Mech Rock Eng 47:1183-1195. https://doi.org/10. 1007/s00603-013-0479-3

Yu M-H (2002) Advances in strength theories for materials under complex stress state in the 20th Century. Appl Mech Rev 55:169218. https://doi.org/10.1115/1.1472455

Yu L, Wang T-C (2019) Generalized Mohr-Coulomb strain criterion for bulk metallic glasses under complex compressive loading. Sci Rep 9:12554. https://doi.org/10.1038/s41598-019-49085-1

Yu M, Xia G, Kolupaev VA (2009) Basic characteristics and development of yield criteria for geomaterials. J Rock Mech Geotech Eng 1:71-88. https://doi.org/10.3724/SP.J.1235.2009.00071
Zhang N, Sheng Z, Li X et al (2011) Study of relationship between Poisson's ratio and angle of internal friction for rocks (in Chinese). Yanshilixue Yu Gongcheng Xuebao Chin J Rock Mech Eng 30:2599-2609

Zhang L, Yang D, Chen Z (2019) Deformation and failure characteristics of weathered granite under uniaxial compression. AIP Adv 9:075222. https://doi.org/10.1063/1.5113661

Zhao K, Huang Z, Yu B (2018) Damage characterization of red sandstones using uniaxial compression experiments. RSC Adv 8:40267-40278. https://doi.org/10.1039/C8RA06972G

Zheng Y, Deng S (2015) Failure probability model considering the effect of intermediate principal stress on rock strength. Math Probl Eng 2015:1-7. https://doi.org/10.1155/2015/960973

Publisher's Note Springer Nature remains neutral with regard to jurisdictional claims in published maps and institutional affiliations. 